\title{
EIF4EBP1 is transcriptionally upregulated by MYCN and associates with poor prognosis in neuroblastoma
}

Kai Voeltzke ${ }^{1}$, Katerina Scharov ${ }^{1,2}$, Cornelius Funk ${ }^{3,4,5}$, Alisa Kahler ${ }^{1}$, Daniel Picard ${ }^{1,2,6}$, Laura Hauffe $^{1}$, Martin F. Orth ${ }^{3}$, Marc Remke ${ }^{1,2,6}$, Irene Esposito ${ }^{7}$, Thomas Kirchner ${ }^{8,9}$, Alexander Schramm ${ }^{10}$, Barak Rotblat ${ }^{11}$, Thomas G. P. Grünewald ${ }^{3,4,5,12}$, Guido Reifenberger ${ }^{1,6}$, Gabriel Leprivier $^{1 *}$

${ }^{1}$ Institute of Neuropathology, Heinrich Heine University, Medical Faculty, and University Hospital Düsseldorf, Düsseldorf, Germany.

2Department of Pediatric Oncology, Hematology, and Clinical Immunology, Heinrich Heine University, Medical Faculty, and University Hospital Düsseldorf, Düsseldorf, Germany. ${ }^{3}$ Max-Eder Research Group for Pediatric Sarcoma Biology, Institute of Pathology, Faculty of Medicine, LMU Munich, Munich, Germany.

${ }^{4}$ Division of Translational Pediatric Sarcoma Research, German Cancer Research Center (DKFZ), Heidelberg, Germany.

${ }^{5}$ Hopp Children's Cancer Center (KiTZ), Heidelberg, Germany.

${ }^{6}$ German cancer consortium (DKTK), partner site Essen/Düsseldorf, Düsseldorf, Germany. ${ }^{7}$ Institute of Pathology, Heinrich Heine University, Medical Faculty, and University Hospital Düsseldorf, Düsseldorf, Germany.

${ }^{8}$ Institute of Pathology, Faculty of Medicine, LMU Munich, Munich, Germany.

${ }^{9}$ German cancer consortium (DKTK) partner site Munich, Munich, Germany.

${ }^{10}$ Department of Medical Oncology, West German Cancer Center, University of Duisburg-

Essen, Essen, Germany.

${ }^{11}$ Department of Life Sciences, Ben-Gurion University of the Negev, Beer Sheva, Israel; The National Institute for Biotechnology in the Negev, Beer Sheva, Israel.

${ }^{12}$ Institute of Pathology, Heidelberg University Hospital, Heidelberg, Germany.

\section{${ }^{*}$ Corresponding author:}

Dr. Gabriel Leprivier, Institute of Neuropathology, Heinrich Heine University Düsseldorf, Moorenstrasse 5, D-40225 Düsseldorf, Germany; E-mail: gabriel.leprivier@med.uniduesseldorf.de. 


\section{ABSTRACT}

\section{Background}

Neuroblastoma (NB) accounts for $15 \%$ of cancer-related deaths in childhood despite considerable therapeutic improvements. While several risk factors, including MYCN amplification and alterations in RAS and p53 pathway genes, have been defined in NB, the clinical outcome is very variable and difficult to predict. Since genes of the mTOR pathway are up-regulated in $M Y C N$-amplified NB, we aimed to define the predictive value of the mTOR substrate-encoding gene eukaryotic translation initiation factor 4E-binding protein 1 (EIF4EBP1) expression in NB patients.

\section{Methods}

Several independent NB patient cohorts with corresponding mRNA expression data were analyzed for EIF4EBP1 expression. An institutional NB cohort consisting of 69 prospectively collected tumors was employed to immunohistochemically analyze expression of EIF4EBP1encoded protein (4EBP1). In addition, we performed an in vitro luciferase reporter gene assay with an episomal EIF4EBP1 promoter and genetically modulated $M Y C N$ expression in NB cells.

\section{Findings}

EIF4EBP1 mRNA expression was positively correlated with MYCN expression and elevated in stage 4 and high-risk NB patients. High EIF4EBP1 mRNA expression was associated with reduced overall and event-free survival in the entire group of NB patients in three cohorts, as well as in stage 4 and high-risk patients. High levels of 4EBP1 were significantly associated with prognostically unfavorable NB histology. Functional analyses in vitro revealed that EIF4EBP1 expression is transcriptionally controlled by MYCN binding to the EIF4EBP1 promoter.

\section{Interpretation}

High EIF4EBP1 expression is associated with poor prognosis in NB patients and may serve to stratify patients with high-risk NB.

\section{Funding}


G.L. was supported by funding from the Elterninitiative Düsseldorf e.V., the Research Commission of the Medical Faculty of Heinrich Heine University, the Deutsche Forschungsgemeinschaft (Grant LE 3751/2-1), and the German Cancer Aid (Grant 70112624). The laboratory of T.G.P.G. is supported by the Barbara und Wilfried Mohr Foundation. BR is supported by the Israel Science Foundation (grant No. 1436/19).

Abstract word count (excluding funding section): 243 words.

Key words: Neuroblastoma, MYCN, mTOR, 4EBP1

\section{RESEARCH IN CONTEXT}

\section{Evidence before this study}

NB represents a particularly heterogeneous cancer entity, with 5-year event-free survival rate ranging from $50 \%$ to $98 \%$ depending on the patient's risk group. While genes of the nutrientsensing mTOR pathway were found to be up-regulated in $M Y C N$-amplified NB tumors, their clinical relevance and prognostic value in NB patients remain unclear. In particular, the mTOR substrate-encoding gene EIF4EBP1 was studied in NB by three different groups and high EIF4EBP1 mRNA expression was observed in MYCN-amplified or contradictorily in more favorable stages 1 and 2 patients. Also, EIF4EBP1 was included in a prognostic gene signature for poor overall survival in NB. However, the prognostic value of EIF4EBP1 alone was not determined in NB and the expression of EIF4EBP1 encoded protein, 4EBP1, was not analyzed in NB tumor tissues and not correlated with clinicopathological features such as histological subtypes. Additionally, the transcriptional regulation of the EIF4EBP1 promoter by MYCN was not characterized.

\section{Added value of this study}

This study uncovers the prognostic potential of EIF4EBP1 at the mRNA and protein levels in NB patients. We report that high EIF4EBP1 expression is correlated with poor survival in three independent cohorts and that high 4EBP1 levels is associated with a prognostically unfavorable histological subtype. High EIF4EBP1 expression is also a factor of poor 
prognosis in stage 4 and high-risk patient groups. Finally, we found that MYCN activates the human EIF4EBP1 promoter through binding at three binding motifs.

\section{Implications of all the available evidence}

EIF4EBP1 mRNA and 4EBP1 protein expression have prognostic value in NB, especially to stratify patients with advanced and more aggressive NB, such as patients with stage 4 disease and high-risk patients including those with unfavorable histological subtype NB. Enhanced EIF4EBP1 mRNA and 4EBP1 protein expression in NB are driven by direct transcriptional activation of EIF4EBP1 by MYCN. 


\section{INTRODUCTION}

Neuroblastoma (NB) is a pediatric malignant tumor that develops from progenitor cells of the sympathetic nervous system and the adrenal glands $[1,2]$. NB is the most commonly occurring extracranial solid tumor in childhood and the major cause of cancer-related mortality in infants [2]. NB tumors are classified into five stages (1, 2, 3, 4 and 4S) according to tumor size, the presence of metastasis and the outcome of surgical resection [1]. Noteworthy, stage $4 \mathrm{~S}$ represents a special form of NB in infants that is associated with a high chance of spontaneous regression despite metastatic spread [1]. Apart from surgical resection, treatment options may include response-adjusted chemotherapy for low to intermediate risk groups or a mix of surgery, high-dose chemotherapy, immunotherapy, and radiation for patients belonging to the high-risk group. The risk level is determined based on the tumor stage combined with age at diagnosis, tumor ploidy, genetic alterations and tumor histology $[1,3]$. However, NB represents a particularly heterogeneous type of cancer, posing challenges to precisely predict therapeutic response and clinical outcome in the individual patient $[4,5]$. While some NB tumors may spontaneously regress, high-risk patients have an increased likelihood of relapse and available treatment options for relapsed patients are rarely successful. Indeed, the 5-year event-free survival rate for high-risk patients is less than $50 \%$, in contrast to $90-98 \%$ for low-risk patients [6]. In addition, success rates of second line treatment in relapsed patients remain poor $[5,7]$. Therefore, it is critical to define novel stratification factors for NB patients to better predict individual risk and to facilitate administration of the most appropriate therapeutic option.

NB is rarely familial (1-2\%) and only few predisposition genes, such as $P H O X 2 B$ and $A L K$, have been reported [4,8-10]. Genetically, several acquired alterations have been detected in NB and linked to patient outcome. These include gain-of-function mutations in $A L K$, gain of chromosome arm 17q, loss of chromosome arm 11q, amplification of MYCN [4], and, more recently reported, alterations in genes related to the RAS and p53 pathways [11]. MYCN amplification is found in about $20 \%$ of NB and is associated with aggressive tumors, therapy resistance and poor survival [6]. MYCN is a member of the MYC oncogene family and 
bioRxiv preprint doi: https://doi org/10.1101/2021.12 08.471784; this version posted December 9 , 2021. The copyright holder for this preprint (which was not certified by peer review) is the author/funder, who has granted bioRxiv a license to display the preprint in perpetuity. It is made available under aCC-BY-NC-ND 4.0 International license.

encodes a transcription factor that recognizes a specific DNA element referred to as E-box $[12,13]$. This allows MYCN to regulate the transcription of genes involved in cell cycle progression, proliferation, differentiation and survival [6]. MYCN is a strong driver of NB tumorigenesis, as tissue-specific overexpression of MYCN is sufficient to induce NB tumor development in mouse models [14]. Mechanistically, MYCN is proposed to rewire metabolism to enable NB tumor cells to proliferate, in turn preserving the intracellular redox balance while producing enough energy by inducing a glycolytic switch [15-17]. In particular, MYCN actively augments the transcription of multiple genes whose products are involved in the protein synthesis machinery [16]. Even though MYCN represents a highly attractive therapeutic target in NB, as a transcription factor that lacks hydrophobic pockets which can be targeted by drug-like small molecules, it is still considered as being "undruggable" [18,19]. Thus, identification of downstream effectors involved in MYCN-driven NB progression is a promising approach to uncover novel targets for molecularly guided therapeutic approaches. To better delineate the molecular basis of $M Y C N$-amplified NB aggressiveness, several approaches have been undertaken. In particular, RNA-sequencing (RNA-seq) has been used to uncover the set of genes induced in $M Y C N$-amplified compared to MYCN-non-amplified NB [20]. Strikingly, this analysis identified regulators of protein synthesis which are components of the mechanistic target of rapamycin (mTOR) pathway, including the mTOR target eukaryotic initiation factor 4E binding protein 1 (EIF4EBP1). The corresponding protein, 4EBP1, is inhibited through mTOR-mediated phosphorylation when nutrients are available, leading to active mRNA translation initiation [21]. Under nutrient-deprived conditions, when mTOR is inhibited, 4EBP1 gets activated and thus binds to the translation initiation factor elF4E, in turn blocking cap-dependent mRNA translation initiation [21]. At the cellular level, 4EBP1 is negatively regulating proliferation and mitochondrial activity [22,23]. The exact role of 4EBP1 in cancer is still debated. 4EBP1 was found to exert a tumor suppressive function in vivo, as 4EBP1 knock-out leads to enhanced tumor formation in mouse models of head and neck squamous cell carcinoma [24], and prostate cancer [25]. In contrast, 4EBP1 was shown to mediate angiogenesis and facilitate tumor growth in a breast 
cancer model in vivo, highlighting a cancer type-specific function of 4EBP1 [26]. In keeping with that, the clinical relevance of EIF4EBP1 expression depends on the tumor type.

EIF4EBP1 was reported to be overexpressed in a number of tumor entities in adults [27], including breast cancer [28], in which EIF4EBP1 is amplified as part of the 8p11-12 amplicon, as well as in ovarian and prostate cancer [29,30]. In breast and liver cancer, high EIF4EBP1 expression has been associated with poor survival [28,31]. In contrast, EIF4EBP1 expression was found to be reduced in head and neck cancer, in which low expression is correlated with poor prognosis [24]. In NB, the expression of EIF4EBP1 is deregulated, even though contradictory findings have been reported. While EIF4EBP1 was characterized as a gene upregulated in $M Y C N$-amplified versus $M Y C N$-non-amplified NB tissues and cells [20], another study reported that EIF4EBP1 levels were higher in favorable stages of NB as compared to advanced stage 4 tumors [32]. In addition, Meng et al. showed that EIF4EBP1 is part of a gene signature that predicts poor overall survival [33]. However, it was not investigated whether EIF4EBP1 expression alone can predict NB patient prognosis. Thus, the clinical relevance of EIF4EBP1 expression in NB needs further evaluation.

Overexpression of EIF4EBP1 in cancer is mediated by certain transcription factors, such as MYC [34], androgen receptor [35], and the stress regulators ATF4 [36] and HIF-1 $\alpha$ [37], which all bind to and thereby modulate the activity of the EIF4EBP1 promoter. More specifically, ChIP-sequencing (ChIP-seq) revealed binding of MYCN to the EIF4EBP1 promoter in NB cells, and MYCN was reported to impact EIF4EBP1 transcription, pointing to EIF4EBP1 as a potential MYCN target gene $[38,39]$. However, how MYCN exactly controls the EIF4EBP1 promoter is still poorly understood.

In this study, we analyzed publicly available NB patient data sets and revealed that EIF4EBP1 is overexpressed in NB compared to normal tissues, is significantly co-expressed with $M Y C N$, and is elevated in high-risk relatively to low-risk tumor groups. High EIF4EBP1 levels were found to be significantly linked to poor overall survival in all NB patients, as well as in the more aggressive stage 4 and high-risk groups. In addition, immunohistochemistry staining of NB tissues confirmed the mRNA-based associations and showed that high 4EBP1 
protein expression associates with unfavorable histology in NB. Finally, by applying gene reporter assays and by modulating MYCN expression in vitro, we found that MYCN upregulates the EIF4EBP1 promoter activity by binding to three distinct E-boxes.

\section{MATERIALS AND METHODS}

\section{Databases}

The RNA-seq, microarray and ChIP-seq data were retrieved from 'R2: Genomics Analysis and Visualization Platform' (http://r2.amc.nl). Data were visualized with IGV or Affinity Designer. For the MYCN occupancy profile in BE(2)-C cells, the ChIP-seq data by Durbin et al. (GSE94824) were accessed using the human genome GRCh 38/hg 38. For the initial across dataset analysis, four publicly available and independent cohorts, namely the Versteeg et al. (GSE16476), Lastowska et al. (GSE13136), Hiyama et al. (GSE16237), and

Delattre et al. (GSE14880) datasets were used. The remaining expression, amplification and survival data consisted of the independent SEQC/ MAQC-III Consortium GSE49710), Kocak et al. study (GSE45547) and Neuroblastoma Research Consortium [NRC] (GSE49710), Kocak (GSE45547) and NRC (GSE85047) cohorts. For the expression analysis of TH-MYCN transgenic NB model, the dataset from Balamuth et al. (GSE17740) was used.

\section{Immunohistochemistry}

For immunohistochemistry, deparaffinated tissue sections were pretreated with citrate buffer at $98^{\circ} \mathrm{C}$ for $20 \mathrm{~min}$, cooled down to room temperature, and blocked with $2 \%$ horse serum, avidin blocking solution and biotin blocking solution (Avidin/Biotin Blocking Kit, SP-2001, Vector Laboratories, Burlingame, CA, USA) for 10 min each. Staining for 4EBP1 was carried out with monoclonal anti-4EBP1 raised in rabbit (1:200; ab32024, Abcam, Cambridge, UK) for $2 \mathrm{~h}$ at $37^{\circ} \mathrm{C}$. Detection was carried out using the Dako REAL detection system, alkaline phosphatase/RED, rabbit/mouse following manufacturer's instructions (Detection Kit \#K5005, Agilent Technologies, Santa Clara, CA, USA). Immunostained tissue sections were 
counterstained with hematoxylin solution according to Mayer (T865.1, Roth, Karlsruhe, Germany).

Evaluation of immunoreactivity of 4EBP1 was carried out in analogy to scoring of hormone receptor Immune Reactive Score (IRS) ranging from 0-12. The percentage of cells with expression of the given antigen was scored and classified in five grades (grade $0=0-19 \%$, grade $1=20-39 \%$, grade $2=40-59 \%$, grade $3=60-79 \%$ and grade $4=80-100 \%)$. In addition, the intensity of marker immunoreactivity was determined (grade $0=$ none, grade $1=$ low, grade $2=$ moderate and grade $3=$ strong). The product of these two grades defined the final IRS. IRS 0-6 was considered as "low" staining level while IRS 7-12 was categorized as "high" staining level.

Tissue microarrays (TMAs) were constructed by taking three representative cores (each 1 $\mathrm{mm}$ in diameter) from respective blocks exhibiting at least $80 \%$ viable tumor tissue. Tumor blocks were retrieved from the archives of the Institutes of Pathology of the LMU Munich or the University Hospital Düsseldorf with IRB approval (study numbers 550-16 UE for LMU Munich and 2018-174 for the University Hospital Düsseldorf).

\section{Statistics}

All experiments were, if not otherwise stated, independently carried out at least three times.

Statistical significance was calculated using Student's t-test or Mann-Whitney U-test in GraphPad Prism 8. For survival analysis, the cohorts were stratified based on relative expression of EIF4EBP1. The median was chosen as expression cutoff to determine high and low EIF4EBP1 level. Statistical significance was determined by the logrank test. Multivariate analysis was performed using the Cox Regression method in SPSS v21 (IBM). To calculate significance of the scoring of immunohistochemistry staining, the Chi-square test was used. The data are represented as means +/- standard deviation. A p-value of less than 0.05 was considered significant. 


\section{Cell culture}

Cells were maintained using standard tissue culture procedures in a humidified incubator at $37^{\circ} \mathrm{C}$ with $5 \% \mathrm{CO}_{2}$ and atmospheric oxygen. NB cell lines IMR-32 and Kelly, and HEK-293-T cells were obtained from American Type Culture Collections (ATCC, Manassas, VA, USA). SHEP-TR-MYCN engineered NB cell lines have been previously described [17]. NB cell lines were cultured in Roswell Park Memorial Institute (RPMI)-1640 medium (Thermo Fisher Scientific, Waltham, MA, USA), while HEK-293-T cells were maintained in Dulbecco's modified Eagle medium (DMEM) (Thermo Fisher Scientific). All cell culture media were supplemented with 10\% (volume/volume) fetal bovine serum (FBS) (Sigma-Aldrich, St. Louis, MI, USA) and 1\% penicillin/streptomycin (Thermo Fisher Scientific). Cells were treated with 3 $\mu \mathrm{g} / \mathrm{ml}$ plasmocin (Invivogen, San Diego, CA, USA) to prevent mycoplasma contamination. To induce MYCN expression, SHEP-TR-MYCN cells were treated with $1 \mu \mathrm{g} / \mathrm{ml}$ doxycycline. All cell lines were routinely confirmed to be mycoplasma-free using Venor®GeM Classic kit (Minerva Biolabs, Berlin, Germany). Cell lines were authenticated by STR-profiling (Genomics and Transcriptomics Laboratory, Heinrich Heine University, Germany).

\section{RNA extraction, cDNA synthesis and quantitative real time PCR}

Total RNA was purified from cells using the RNeasy plus mini kit (QIAgen, Hilden, Germany) according to the manufacturer's handbook. RNA concentration and purity were assessed by spectrophotometry using the NanoDrop2000 (Thermo Fisher Scientific). Subsequently, each sample was diluted to a concentration of $100 \mathrm{ng} / \mu \mathrm{l}$ in nuclease-free water. For cDNA synthesis, $1 \mu \mathrm{g}$ RNA was processed in a total reaction volume of $20 \mu \mathrm{l}$ using the HighCapacity cDNA Reverse Transcription kit (Applied Biosystems, Waltham, MA, USA), following the manufacturer's protocol. Quantitative real time reverse transcription PCR was performed using SYBR green PCR master mix (Applied Biosystems) and the CFX384 Touch Real-Time PCR Detection System (Bio-Rad Laboratories, Hercules, CA, USA). Relative 
expression levels of $M Y C N$ and EIF4EBP1 were normalized to internal housekeeping genes GUSB and PPIA. The primer list can be found in supplementary table 1.

\section{Immunoblot analysis of protein expression}

Cells were washed with phosphate buffered saline (PBS) and lysed in radioimmunoprecipitation assay (RIPA) buffer (150 mM NaCl, $50 \mathrm{mM}$ Tris- $\mathrm{HCl}, \mathrm{pH} 8,1 \%$ Triton X-100, 0.5\% sodium deoxycholate, and $0.1 \%$ SDS) supplemented with protease inhibitors (Sigma-Aldrich) and phosphatase inhibitors mix (PhosphoSTOP, Roche, Penzberg, Germany). Cell lysates were centrifuged at $21,000 \mathrm{rpm}$ for $15 \mathrm{~min}$ at $4^{\circ} \mathrm{C}$ to separate cell debris and DNA from protein lysates. Protein concentration was measured with the BCA protein assay kit (Thermo Fisher Scientific), according to manufacturer's protocol. Protein lysates were separated by SDS-PAGE and transferred onto a nylon membrane. The membrane was incubated for $1 \mathrm{~h}$ in Tris-buffered saline Tween (TBST) (50 mM Tris-Cl, 150 $\mathrm{mM} \mathrm{NaCl}, \mathrm{pH} 7.5,0.1 \%$ Tween-20) containing $5 \%$ bovine serum albumin (BSA), to prevent non-specific antibody binding, followed by an overnight incubation at $4{ }^{\circ} \mathrm{C}$ with the following primary antibodies: 4EBP1 (1:1,000, Cell Signaling Technology, Cambridge, UK \#9644), MYCN (1:1,000, Cell Signaling \#9405), GAPDH (1:1,000, Cell Signaling \#2118), and $\beta$-Actin (1:5,000, Sigma-Aldrich \#A2228). The secondary antibodies IRDye 800CW Goat anti-Rabbit (1:10,000, LI-COR Biosciences, Bad Homburg, Germany \#926-32211) or IRDye 800CW Goat anti-Mouse (1:10,000, LI-COR Biosciences \#926-32210) were incubated at room temperature for $1 \mathrm{~h}$, followed by detection of the fluorescent signal with the Odyssey CLx imager (LI-COR Biosciences).

\section{Plasmid construction}

The promoter region of the human EIF4EBP1 gene, spanning from -192 to +1372 , was inserted into the Sacl and Bglll restriction sites of the Firefly Luciferase expressing pGL4.22 
plasmid (Promega, Madison, WI, USA). Each of the three identified MYCN binding site was subsequently mutated alone or in a combination of two sites. Each of the E-box sequence has been mutated to CAAGGC. All cloning was performed by GENEWIZ Germany GmbH (Leipzig, Germany).

\section{Luciferase Reporter Assay}

For the promoter reporter assay, HEK-293-T cells were seeded into 12-well plates and cotransfected the following day with $500 \mathrm{ng}$ of the EIF4EBP1 WT or mutant promoter pGL4.22 plasmids, $50 \mathrm{ng}$ of the MYCN overexpressing pcDNA3.1 plasmid or empty pcDNA3.1 plasmid, and $3 \mathrm{ng}$ of the Renilla Luciferase expressing pRL-SV40 plasmid (Promega) for normalization. For transfection, plasmids were incubated with $3 \mu$ l CalFectin (SignaGen laboratories, Rockville, MD, USA) in Opti-MEM (Thermo Fisher Scientific) for 20 min before adding the mix dropwise onto the cells. $48 \mathrm{~h}$ post-transfection, cells were passively lysed and processed according to the protocol of the Dual-Luciferase ${ }^{\circledR}$ Reporter Assay System (Promega), besides using only half the recommended volume of detection buffers. Firefly and Renilla luciferase activities were sequentially measured using a Tecan Spark plate reader and the ratio of firefly luciferase to Renilla luciferase luminescence was calculated. The experiments were repeated independently for three times.

\section{RESULTS}

\section{EIF4EBP1 expression is increased in NB and correlates with MYCN expression}

To assess the clinical significance of EIF4EBP1 expression, we first examined EIF4EBP1 mRNA levels in NB tumor tissue samples and normal tissues. We pooled microarray data of four different NB cohorts and retrieved expression data from adrenal tissue used as the corresponding normal tissue (Fig. 1a). This indicated that EIF4EBP1 expression is significantly elevated in NB compared to adrenal gland ( $p<0.0001$, Fig. 1a). We then determined whether EIF4EBP1 expression is related to the MYCN amplification status. By 
comparing the level of EIF4EBP1 in MYCN-amplified versus MYCN-non-amplified NB samples, we found that EIF4EBP1 is expressed at higher levels in $M Y C N$-amplified compared to MYCN-non-amplified NB in the SEQC and Kocak cohorts $[40,41](p<0.0001$, Fig. 1b; $p<0.0001$, Fig. 1c). This further supports and extends previous observations made in a limited number of NB samples $(\mathrm{n}=20)$ showing EIF4EBP1 overexpression in $M Y C N$ amplified versus $M Y C N$-non-amplified NB tumors [20]. Since $M Y C N$ amplification may result in different levels of $M Y C N$, we next investigated whether expression levels of $M Y C N$ and EIF4EBP1 in NB correlate with each other. Our analyses highlight a significant coexpression between MYCN and EIF4EBP1 in the SEQC (correlation coefficient $[r]=0.564, p<0.0001$, Fig. 1d) and Kocak ( $[r]=0.532, p<0.0001$, Fig. 1e) cohorts. These findings are in line with the reports that EIF4EBP1 is a potential MYCN target gene in NB $[38,39]$. We also assessed whether the expression of EIF4EBP1 is determined by NB stages or risk groups, and found that EIF4EBP1 levels are increased according to NB tumor aggressiveness in two cohorts (Fig. 1f\&g). In particular, EIF4EBP1 is expressed at higher levels in stage 4 NB tumors as compared to stage 1 and stage 2 tumors (stage 4 versus stage 1, $p<0.0001$, Fig. 1f; $p<0.0001$ Fig. 1g). Interestingly, samples from stage 4S NB showed significantly lower EIF4EBP1 levels compared to stage 4 tumors (stage 4 S versus stage 4, $\mathrm{p}<0.01$, Fig. 1f; $\mathrm{p}<0.001$, Fig. $1 \mathrm{~g}$ ). In support of this finding, we observed that in the SEQC cohort EIF4EBP1 expression is higher in high-risk compared to low-risk NB, as based on the Children's Oncology Group (COG) classification ( $p<0.0001$, Fig. 1h). Such clinical information was not available in any other publicly available cohorts with mRNA expression data. Taken together, we present evidence that EIF4EBP1 is commonly overexpressed in NB tumors and that EIF4EBP1 level is increased in MYCN-amplified NB and advanced NB stages.

\section{EIF4EBP1 expression is a factor of poor prognosis in NB}

Since we found EIF4EBP1 mRNA levels to be elevated in aggressive NB subsets, we examined whether EIF4EBP1 expression is linked to prognosis in NB patients. Kaplan-Meier estimates univocally showed that high EIF4EBP1 levels (using median expression level as 
cut off) were significantly associated with reduced overall and event-free survival in three independent cohorts, namely SEQC, Kocak and NRC cohorts [42] $(p=3.1 \mathrm{e}-08$, Fig. 2a; p=4.2e-11, Fig. 2b; $p=1.7 e-06$, Fig. 2c, and supplementary Fig. 1a, b\&c). To test dependence of EIF4EBP1 expression as prognostic factor on established factors of poor prognosis, we performed multivariate analysis to determine the statistical interaction between high EIF4EBP1 expression and MYCN amplification status, tumor stage or age at diagnosis. This indicated that MYCN amplification status, tumor stage and age at diagnosis each influenced the prognostic value of high EIF4EBP1 expression in the SEQC and NRC cohorts (Tables 1\&2). Therefore, high EIF4EBP1 expression is not an independent factor of poor prognosis in NB. However, we uncovered that EIF4EBP1 expression can predict overall survival in clinically relevant NB subsets, including more advanced and aggressive NB subgroups. Indeed, our analyses highlighted that high EIF4EBP1 expression significantly predicted reduced overall survival in MYCN-non-amplified patients of the SEQC and NRC cohorts $(p=3.8 e-03$, Fig. $2 d ; p=0.04$, Fig. $2 e)$, while it was significant for event-free survival only in the SEQC cohort (supplementary Fig. 1d\&e). On the other hand, Kaplan-Meier survival estimates in high-risk NB patients (SEQC cohort) revealed that high EIF4EBP1 levels were correlated with poor overall survival ( $p=7.4 e-03$, Fig. $2 f)$, as well as with reduced event-free survival (supplementary Fig. 1f), suggesting that EIF4EBP1 expression can stratify patients within the most aggressive NB subset. We additionally analyzed the prognostic value of EIF4EBP1 expression in stage 4 NB patients. We found high EIF4EBP1 expression to significantly predict decreased overall and event-free survival of stage 4 patients in two independent cohorts (SEQC and NRC cohorts) ( $p=3.2 e-04$ Fig. $2 g ; p=3.8 e-03$, Fig. $2 h$ and supplementary Fig. 1g\&h). This highlights that EIF4EBP1 expression robustly stratifies patients within the advanced NB subgroups. Altogether, our analyses support that EIF4EBP1 expression is a factor of poor prognosis in all NB, as well as in high-risk and stage 4 NB.

\section{High 4EBP1 protein expression is associated with prognostically unfavorable histology of NB}


To independently confirm the prognostic value of EIF4EBP1/4EBP1 in NB and to determine the biomarker potential of 4EBP1 protein expression in NB, we immunohistochemically analyzed NB TMAs consisting of 69 patient samples. Staining of the TMAs with a 4EBP1specific antibody revealed a cytoplasmic staining (Fig. 3a), consistent with the expected cellular localization of 4EBP1 [43]. We semi-quantitatively evaluated 4EBP1 staining intensity and correlated 4EBP1 immunoreactivity with the NB histological subtypes according to the International Neuroblastoma Pathology Classification (INPC), which distinguishes patients with favorable or unfavorable histology based on grade of neuroblastic differentiation and mitosis-karyorrhexis index. We found that tumors with unfavorable histology more frequently exhibited a high 4EBP1 staining score (IRS 7-12) as compared to tumors with favorable histology (Fig. 3b), indicating that high 4EBP1 protein expression is associated with more aggressive NB subsets.

\section{EIF4EBP1 promoter activity and transcription is controlled by MYCN}

To delineate how elevated EIF4EBP1 expression is mechanistically connected to MYCN amplification and overexpression in NB, we investigated the transcriptional regulation of EIF4EBP1 by MYCN. A previous report detected the presence of MYCN on EIF4EBP1 promoter by ChIP in BE(2)-C, a MYCN-amplified NB cell line $[38,39]$. We validated and further extended this finding by analyzing ChIP-seq data available from an additional MYCNamplified NB cell line, Kelly. This revealed that MYCN binds the endogenous EIF4EBP1 promoter region (which encompasses exon 1 and a part of intron 1) at three distinct positions, indicating three potential MYCN binding sites (Fig. 4a). In silico analysis of the promoter region sequence confirmed the presence of structural E-boxes at the three occupied locations (Fig. 4b). To evaluate the impact of MYCN on the regulation of EIF4EBP1 promoter activity, we designed a luciferase-based gene reporter assay by cloning the EIF4EBP1 promoter region $(-192$ to +1372$)$ in front of a Firefly Luciferase gene (Fig. 4b). The activity of the wildtype EIF4EBP1 promoter was dose-dependently increased upon forced expression of MYCN in HEK-293-T cells (supplementary Fig. 2a), which was accompanied 
by an upregulation of endogenous 4EBP1 protein level (supplementary Fig. 2b). To investigate which E-boxes are necessary for the transcriptional activation of the EIF4EBP1 promoter by MYCN, either a single or a combination of two of the three potential binding sites were mutated. Mutation of either of the three binding sites alone was sufficient to reduce MYCN-induced promoter activity by at least 50\% (Fig. 4c). Any combinations of two mutated binding sites virtually abolished promoter activity driven by MYCN overexpression (Fig. 4c), suggesting that two binding sites, without a specific preference of one over another, are needed for full induction of EIF4EBP1 promoter activity by MYCN. We next intended to confirm whether MYCN directly regulates EIF4EBP1 transcription in NB cell lines. To do so, we chose two MYCN-amplified NB cell lines, IMR-32 and Kelly, in which we knocked down MYCN expression by siRNA and examined the impact on EIF4EBP1 mRNA levels by qPCR. The depletion of $M Y C N$ caused a significant reduction of EIF4EBP1 transcript levels in both cell lines (Fig. 4d\&e). To further support these observations, we assessed the impact of forced MYCN expression on EIF4EBP1 transcript and protein levels by using SHEP-TRMYCN cells, which are MYCN-non-amplified NB cells engineered to express exogenous MYCN with a tetracycline inducible system [17]. Doxycycline treatment markedly increased EIF4EBP1 mRNA level over time (Fig. 4f), in parallel with progressive upregulation of MYCN expression (Fig. 4g). This was accompanied by a net increase in the 4EBP1 protein level (Fig. 4g), supporting that MYCN positively controls EIF4EBP1 mRNA and protein expression in NB cells. In accordance with these findings, analyses of expression data from a transgenic mouse model of MYCN-driven NB (TH-MYCN; [44]) revealed that EIF4EBP1 expression is upregulated in NB tumors as compared to the corresponding normal tissue, i.e. the ganglia (Fig. 4h). Taken together, our data provide further evidence that EIF4EBP1 is a transcriptional target of MYCN, potentially providing a mechanistic basis for the observed overexpression of EIF4EBP1 in MYCN-amplified NB patients.

\section{DISCUSSION}


MYCN-amplification is accountable for aggressive NB subsets as it has been associated with increased risk of relapse and reduced overall survival of patients [6]. Since MYCN is considered "undruggable", there is a demand for identifying targetable downstream effectors of MYCN $[18,19]$. In addition, since NB is a clinically heterogenous disease, ranging from spontaneous regression to progression despite aggressive therapies, novel markers that improve patient risk stratification and hence allow for optimal treatment allocation are warranted [4]. Here, we report that EIF4EBP1 expression levels are significantly elevated in NB compared to corresponding non-tumor tissues and positively correlate with both MYCN expression and MYCN amplification status in at least two independent NB patient cohorts. Furthermore, using three independent NB cohorts, we report that high EIF4EBP1 expression is a strong predictor of poor overall and event-free survival across all NB patients. This was not independent of MYCN amplification status, tumor stage or age at diagnosis, which can be explained in part by the regulation of EIF4EBP1 promoter by MYCN which we characterized. However, EIF4EBP1 expression can predict prognosis within distinct patient groups like the MYCN-non-amplified patients subset, for which little biomarkers have been identified. Moreover, we observed that high EIF4EBP1 expression was associated with poor prognosis in the group of patients with aggressive stage 4 NB. Of note, less than a third of stage 4 patients carry a MYCN amplification. Thus, it may be worth considering that, in addition to MYCN amplification status, levels of EIF4EBP1 expression could help identifying patients carrying clinically more aggressive tumors within the stage 4 NB patients group. EIF4EBP1 expression was also linked to worse outcome among high-risk NB patients. Given that MYCN amplification is not able of predicting outcome within high-risk NB patients [45], it appears that EIF4EBP1 expression has a prognostic power beyond $M Y C N$ amplification in this patient subset. Thus, EIF4EBP1 expression may represent a promising biomarker for prognostic stratification of high-risk NB patients, in addition to the recently reported genetic alterations in the RAS and p53 pathways [11]. This is further supported by the association we observed between high 4EBP1 protein expression and unfavorable NB histological subtype. Together, our findings highlight a previously underappreciated prognostic factor, i.e., 
bioRxiv preprint doi: https://doi.org/10.1101/2021.12.08.471784; this version posted December 9, 2021. The copyright holder for this preprint (which was not certified by peer review) is the author/funder, who has granted bioRxiv a license to display the preprint in perpetuity. It is made available under aCC-BY-NC-ND 4.0 International license.

EIF4EBP1/4EBP1, which may help refining risk stratification of NB patients, including $M Y C N$ non-amplified, stage 4 and high-risk patients, and could potentially assist in tailoring more personalized treatment options. Beyond NB, EIF4EBP1 expression was reported to be a factor of poor prognosis in breast and liver cancers [28,31], as well as in all TCGA tumor types combined [27]. While our data indicate that EIF4EBP1 expression has prognostic power in pediatric cancer, together this supports that EIF4EBP1 expression represents a factor of poor prognosis in a large number of different tumor types.

Our study also extends previous knowledge by providing further experimental evidence to explain the association between EIF4EBP1 and MYCN expression in NB and the overexpression of EIF4EBP1 in MYCN-amplified NB. Our data revealed that MYCN induces transcription of EIF4EBP1 by regulating its promoter through multiple binding sites, which was originally suggested by detection of MYCN binding to the EIF4EBP1 promoter by ChIP analysis $[38,39]$. However, whether MYCN could transcriptionally regulate the EIF4EBP1 promoter was still elusive. We demonstrate that MYCN activates the EIF4EBP1 promoter through binding at three distinct E-boxes, which in turn leads to transcriptional increase of EIF4EBP1. Together with the previous ChIP analysis, this supports that EIF4EBP1 is a direct target gene of MYCN in NB cells. These findings are in line with a previous study reporting that MYC controls EIF4EBP1 by binding its endogenous promoter in colorectal cancer cells [46], highlighting a general regulation of EIF4EBP1 by MYC family members in cancer cells. Expression levels of EIF4EBP1 appear not only elevated in $M Y C N$-amplified versus $M Y C N$ non-amplified NB but are also upregulated in $M Y C N$-non-amplified tumors relative to control tissue. It might be speculated that in MYCN-non-amplified NB, EIF4EBP1 expression may be regulated by transcription factors other than MYCN. In particular, ATF4, which is critical for the metabolic response of NB cells to glutamine starvation $[47,48]$, has been shown to control EIF4EBP1 promoter and transcription in pancreatic beta cells [36]. This transcription factor is highly expressed in NB, and in particular in advanced stage 4 [48]. In addition, another transcription factor that is commonly overexpressed in NB is OCT4 [49]. Of note, this transcription factor has been identified by ChIP-seq to bind the promoter region of EIF4EBP1 
in human embryonic stem cells [50,51], thus OCT4 may also activate EIF4EBP1 transcription in NB cells. Together, these data suggest potential mechanisms underlying the MYCN independent regulation of EIF4EBP1 expression in MYCN-non-amplified NB patients. Given the prognostic significance of EIF4EBP1/4EBP1 in NB, it is possible that 4EBP1 confers advantages to NB tumor growth or tumor cell survival. As evidenced by the presence of necrotic areas flanked by HIF-1 $\alpha$ positive staining [52], NB experience metabolic stress, corresponding to nutrient deprivation and hypoxia, as a consequence of abnormal and immature vascularization $[53,54]$. One important mechanism for cancer cells to adapt to metabolic stress is through reprogramming of mRNA translation [55]. As a major regulator of mRNA translation, 4EBP1 may aid NB cells to cope with hypoxia and nutrient deprivation. This is supported by the report that 4EBP1 promotes survival of breast tumors under hypoxia by stimulating the synthesis of pro-angiogenic factors, like HIF-1 $\alpha$ and VEGF, to facilitate tumor angiogenesis in vivo [26]. In addition, the control of mRNA translation was shown to be critical to prevent the deleterious effects of MYCN and MYC overexpression, as we and others previously reported $[46,56]$. In fact, 4EBP1, by reducing overall protein synthesis, was reported to prevent cell death induced upon MYC overexpression, likely by blunting accumulation of misfolded proteins and proteotoxic ER stress [46]. It is possible that in a similar manner 4EBP1 contributes to inhibit cell death induced by MYCN overexpression in MYCN-amplified NB.

In summary, the findings reported here indicate that EIF4EBP1 is a direct target gene of MYCN in NB, explaining the observed high expression of EIF4EBP1 in NB, and that EIF4EBP1 mRNA and protein expression have prognostic values in NB patients, especially for stratifying high-risk NB patients.

\section{AUTHORS CONTRIBUTION}

Conception and design: Kai Voeltzke and Gabriel Leprivier.

Provision of study material and patients: Irene Esposito and Thomas Kirchner.

Financial and administrative support: Guido Reifenberger. 
Data analysis and interpretation: Kai Voeltzke, Thomas G. P. Grünewald, Alexander

Schramm and Gabriel Leprivier.

Critical review and discussion: Barak Rotblat, Marc Remke, Alexander Schramm, Guido

Reifenberger and Gabriel Leprivier.

Experimental support: Kai Voeltzke, Katerina Scharov, Cornelius Funk, Alisa Kahler, Daniel

Picard, Laura Hauffe and Martin F. Orth.

Manuscript writing: Kai Voeltzke, Guido Reifenberger and Gabriel Leprivier.

Final approval of the manuscript: All authors.

\section{DECLARATION OF INTERESTS}

Thomas Kirchner received honoraria for Consulting/Advisory by Amgen, AstraZeneca, BMS,

Merck KGaA, MSD, Novartis, Pfizer, Roche, for Research Funding by Merck KGaA and

Roche; for talks by Merck KGaA, AstraZeneca.

The other authors declare no conflict of interest.

\section{ACKOWLEDGMENTS}

We would like to thank Dr. Bastian Malzkorn (Institute of Neuropathology, Heinrich Heine University Düsseldorf) for helpful discussions.

\section{DATA SHARING STATEMENT}

The data that support the findings of this study are available from the corresponding author upon reasonable request.

\section{REFERENCES}

[1] Maris JM, Hogarty MD, Bagatell R, Cohn SL. Neuroblastoma. The Lancet 2007;369(9579):2106-20. https://doi.org/10.1016/S0140-6736(07)60983-0. 
[2] van Arendonk KJ, Chung DH. Neuroblastoma: Tumor Biology and Its Implications for Staging and Treatment. Children (Basel) 2019;6(1).

https://doi.org/10.3390/children6010012.

[3] Tolbert VP, Matthay KK. Neuroblastoma: clinical and biological approach to risk stratification and treatment. Cell Tissue Res 2018;372(2):195-209. https://doi.org/10.1007/s00441-018-2821-2.

[4] Maris JM. The biologic basis for neuroblastoma heterogeneity and risk stratification. Current Opinion in Pediatrics 2005;17(1):7-13. https://doi.org/10.1097/01.mop.0000150631.60571.89.

[5] London WB, Castel V, Monclair T, Ambros PF, Pearson ADJ, Cohn SL et al. Clinical and biologic features predictive of survival after relapse of neuroblastoma: a report from the International Neuroblastoma Risk Group project. J Clin Oncol 2011;29(24):3286-92. https://doi.org/10.1200/JCO.2010.34.3392.

[6] Huang M, Weiss WA. Neuroblastoma and MYCN. Cold Spring Harb Perspect Med 2013;3(10):a014415. https://doi.org/10.1101/cshperspect.a014415.

[7] Simon T, Berthold F, Borkhardt A, Kremens B, Carolis B de, Hero B. Treatment and outcomes of patients with relapsed, high-risk neuroblastoma: results of German trials. Pediatric blood \& cancer 2011;56(4):578-83. https://doi.org/10.1002/pbc.22693.

[8] Chen Y, Takita J, Choi YL, Kato M, Ohira M, Sanada M et al. Oncogenic mutations of ALK kinase in neuroblastoma. Nature 2008;455(7215):971-4. https://doi.org/10.1038/nature07399.

[9] Mossé YP, Laudenslager M, Longo L, Cole KA, Wood A, Attiyeh EF et al. Identification of ALK as a major familial neuroblastoma predisposition gene. Nature 2008;455(7215):930-5. https://doi.org/10.1038/nature07261.

[10] Janoueix-Lerosey I, Lequin D, Brugières L, Ribeiro A, Pontual L de, Combaret V et al. Somatic and germline activating mutations of the ALK kinase receptor in neuroblastoma. Nature 2008;455(7215):967-70. https://doi.org/10.1038/nature07398. 
[11] Ackermann S, Cartolano M, Hero B, Welte A, Kahlert Y, Roderwieser A et al. A mechanistic classification of clinical phenotypes in neuroblastoma. Science (New York, N.Y.) 2018;362(6419):1165-70. https://doi.org/10.1126/science.aat6768.

[12] Zeid R, Lawlor MA, Poon E, Reyes JM, Fulciniti M, Lopez MA et al. Enhancer invasion shapes MYCN-dependent transcriptional amplification in neuroblastoma. Nat Genet 2018;50(4):515-23. https://doi.org/10.1038/s41588-018-0044-9.

[13] Liu R, Shi P, Wang Z, Yuan C, Cui H. Molecular Mechanisms of MYCN Dysregulation in Cancers. Front. Oncol. 2020;10:625332. https://doi.org/10.3389/fonc.2020.625332.

[14] Weiss WA, Aldape K, Mohapatra G, Feuerstein BG, Bishop JM. Targeted expression of MYCN causes neuroblastoma in transgenic mice. The EMBO journal 1997;16(11):298595. https://doi.org/10.1093/emboj/16.11.2985.

[15] Oliynyk G, Ruiz-Pérez MV, Sainero-Alcolado L, Dzieran J, Zirath H, Gallart-Ayala H et al. MYCN-enhanced Oxidative and Glycolytic Metabolism Reveals Vulnerabilities for Targeting Neuroblastoma. iScience 2019;21:188-204. https://doi.org/10.1016/j.isci.2019.10.020.

[16] Boon K, Caron HN, van Asperen R, Valentijn L, Hermus MC, van Sluis P et al. N-myc enhances the expression of a large set of genes functioning in ribosome biogenesis and protein synthesis. The EMBO journal $2001 ; 20(6): 1383-93$. https://doi.org/10.1093/emboj/20.6.1383.

[17] Tjaden B, Baum K, Marquardt V, Simon M, Trajkovic-Arsic M, Kouril T et al. N-Mycinduced metabolic rewiring creates novel therapeutic vulnerabilities in neuroblastoma. Sci Rep 2020;10(1):7157. https://doi.org/10.1038/s41598-020-64040-1.

[18] Bell E, Chen L, Liu T, Marshall GM, Lunec J, Tweddle DA. MYCN oncoprotein targets and their therapeutic potential. Cancer letters 2010;293(2):144-57. https://doi.org/10.1016/j.canlet.2010.01.015.

[19] Wolpaw AJ, Bayliss R, Büchel G, Dang CV, Eilers M, Gustafson WC et al. Drugging the "Undruggable" MYCN Oncogenic Transcription Factor: Overcoming Previous Obstacles 
to Impact Childhood Cancers. Cancer Res 2021;81(7):1627-32.

https://doi.org/10.1158/0008-5472.CAN-20-3108.

[20] Schramm A, Köster J, Marschall T, Martin M, Schwermer M, Fielitz K et al. Nextgeneration RNA sequencing reveals differential expression of MYCN target genes and suggests the mTOR pathway as a promising therapy target in MYCN-amplified neuroblastoma. International Journal of Cancer 2013;132(3):E106-15. https://doi.org/10.1002/ijc.27787.

[21] Musa J, Orth MF, Dallmayer M, Baldauf M, Pardo C, Rotblat B et al. Eukaryotic initiation factor 4E-binding protein 1 (4E-BP1): a master regulator of mRNA translation involved in tumorigenesis. Oncogene 2016;35(36):4675-88. https://doi.org/10.1038/onc.2015.515.

[22] Morita M, Gravel S-P, Chénard V, Sikström K, Zheng L, Alain T et al. mTORC1 controls mitochondrial activity and biogenesis through 4E-BP-dependent translational regulation. Cell Metabolism 2013;18(5):698-711. https://doi.org/10.1016/j.cmet.2013.10.001.

[23] Dowling RJO, Topisirovic I, Alain T, Bidinosti M, Fonseca BD, Petroulakis E et al. mTORC1-mediated cell proliferation, but not cell growth, controlled by the 4E-BPs. Science (New York, N.Y.) 2010;328(5982):1172-6. https://doi.org/10.1126/science.1187532.

[24] Wang Z, Feng X, Molinolo AA, Martin D, Vitale-Cross L, Nohata N et al. 4E-BP1 Is a Tumor Suppressor Protein Reactivated by mTOR Inhibition in Head and Neck Cancer. Cancer Res 2019;79(7):1438-50. https://doi.org/10.1158/0008-5472.CAN-18-1220.

[25] Ding M, van der Kwast TH, Vellanki RN, Foltz WD, McKee TD, Sonenberg N et al. The mTOR Targets 4E-BP1/2 Restrain Tumor Growth and Promote Hypoxia Tolerance in PTEN-driven Prostate Cancer. Mol Cancer Res 2018;16(4):682-95. https://doi.org/10.1158/1541-7786.MCR-17-0696.

[26] Braunstein S, Karpisheva K, Pola C, Goldberg J, Hochman T, Yee H et al. A hypoxiacontrolled cap-dependent to cap-independent translation switch in breast cancer. Molecular cell 2007;28(3):501-12. https://doi.org/10.1016/j.molcel.2007.10.019. 
[27] Wu S, Wagner G. Deep computational analysis of human cancer and non-cancer tissues details dysregulation of elF4F components and their interactions in human cancers. bioRxiv 2020:2020.10.12.336263. https://doi.org/10.1101/2020.10.12.336263.

[28] Karlsson E, Pérez-Tenorio G, Amin R, Bostner J, Skoog L, Fornander T et al. The mTOR effectors 4EBP1 and S6K2 are frequently coexpressed, and associated with a poor prognosis and endocrine resistance in breast cancer: a retrospective study including patients from the randomised Stockholm tamoxifen trials. Breast cancer research BCR 2013;15(5):R96. https://doi.org/10.1186/bcr3557.

[29] Kremer CL, Klein RR, Mendelson J, Browne W, Samadzedeh LK, Vanpatten K et al. Expression of mTOR signaling pathway markers in prostate cancer progression. The Prostate 2006;66(11):1203-12. https://doi.org/10.1002/pros.20410.

[30] Lee M, Kim EJ, Jeon MJ. MicroRNAs 125a and 125b inhibit ovarian cancer cells through post-transcriptional inactivation of EIF4EBP1. Oncotarget 2016;7(8):8726-42. https://doi.org/10.18632/oncotarget.6474.

[31] Cha Y-L, Li P-D, Yuan L-J, Zhang M-Y, Zhang Y-J, Rao H-L et al. EIF4EBP1 overexpression is associated with poor survival and disease progression in patients with hepatocellular carcinoma. PLOS ONE 2015;10(2):e0117493. https://doi.org/10.1371/journal.pone.0117493.

[32] Fransson S, Abel F, Kogner P, Martinsson T, Ejeskär K. Stage-dependent expression of PI3K/Akt-pathway genes in neuroblastoma. International Journal of Oncology 2013;42(2):609-16. https://doi.org/10.3892/ijo.2012.1732.

[33] Meng X, Li H, Fang E, Feng J, Zhao X. Comparison of Stage 4 and Stage 4s Neuroblastoma Identifies Autophagy-Related Gene and LncRNA Signatures Associated With Prognosis. Front. Oncol. 2020;10:1411. https://doi.org/10.3389/fonc.2020.01411.

[34] Balakumaran BS, Porrello A, Hsu DS, Glover W, Foye A, Leung JY et al. MYC activity mitigates response to rapamycin in prostate cancer through eukaryotic initiation factor 4E-binding protein 1-mediated inhibition of autophagy. Cancer Res 2009;69(19):780310. https://doi.org/10.1158/0008-5472.CAN-09-0910. 
[35] Liu Y, Horn JL, Banda K, Goodman AZ, Lim Y, Jana S et al. The androgen receptor regulates a druggable translational regulon in advanced prostate cancer. Science Translational Medicine 2019;11(503). https://doi.org/10.1126/scitranslmed.aaw4993.

[36] Yamaguchi S, Ishihara H, Yamada T, Tamura A, Usui M, Tominaga R et al. ATF4mediated induction of 4E-BP1 contributes to pancreatic beta cell survival under endoplasmic reticulum stress. Cell Metabolism 2008;7(3):269-76. https://doi.org/10.1016/j.cmet.2008.01.008.

[37] Azar R, Lasfargues C, Bousquet C, Pyronnet S. Contribution of HIF-1 $\alpha$ in 4E-BP1 gene expression. Mol Cancer Res 2013;11(1):54-61. https://doi.org/10.1158/15417786.MCR-12-0095.

[38] Cheung CHY, Hsu C-L, Tsuei C-Y, Kuo T-T, Huang C-T, Hsu W-M et al. Combinatorial targeting of MTHFD2 and PAICS in purine synthesis as a novel therapeutic strategy. Cell death \& disease 2019;10(11):786. https://doi.org/10.1038/s41419-019-2033-z.

[39] Hsu C-L, Chang H-Y, Chang J-Y, Hsu W-M, Huang H-C, Juan H-F. Unveiling MYCN regulatory networks in neuroblastoma via integrative analysis of heterogeneous genomics data. Oncotarget 2016;7(24):36293-310. https://doi.org/10.18632/oncotarget.9202.

[40] SEQC/MAQC consortium. SEQC/MAQC consortium: A comprehensive assessment of RNA-seq accuracy, reproducibility and information. Nature biotechnology 2014;32(9):903-14. https://doi.org/10.1038/nbt.2957.

[41] Kocak H, Ackermann S, Hero B, Kahlert Y, Oberthuer A, Juraeva D et al. Hox-C9 activates the intrinsic pathway of apoptosis and is associated with spontaneous regression in neuroblastoma. Cell death \& disease 2013;4(4):e586. https://doi.org/10.1038/cddis.2013.84.

[42] Rajbhandari P, Lopez G, Capdevila C, Salvatori B, Yu J, Rodriguez-Barrueco R et al. Cross-Cohort Analysis Identifies a TEAD4-MYCN Positive Feedback Loop as the Core Regulatory Element of High-Risk Neuroblastoma. Cancer discovery 2018;8(5):582-99. https://doi.org/10.1158/2159-8290.CD-16-0861. 
[43] Armengol G, Rojo F, Castellví J, Iglesias C, Cuatrecasas M, Pons B et al. 4E-binding protein 1: a key molecular "funnel factor" in human cancer with clinical implications. Cancer Res 2007;67(16):7551-5. https://doi.org/10.1158/0008-5472.CAN-07-0881.

[44] Balamuth NJ, Wood A, Wang Q, Jagannathan J, Mayes P, Zhang Z et al. Serial transcriptome analysis and cross-species integration identifies centromere-associated protein E as a novel neuroblastoma target. Cancer Res 2010;70(7):2749-58. https://doi.org/10.1158/0008-5472.CAN-09-3844.

[45] Lee JW, Son MH, Cho HW, Ma YE, Yoo KH, Sung KW et al. Clinical significance of MYCN amplification in patients with high-risk neuroblastoma. Pediatric blood \& cancer 2018;65(10):e27257. https://doi.org/10.1002/pbc.27257.

[46] Tameire F, Verginadis II, Leli NM, Polte C, Conn CS, Ojha R et al. ATF4 couples MYCdependent translational activity to bioenergetic demands during tumour progression. Nature cell biology 2019;21(7):889-99. https://doi.org/10.1038/s41556-019-0347-9.

[47] Qing G, Li B, Vu A, Skuli N, Walton ZE, Liu X et al. ATF4 regulates MYC-mediated neuroblastoma cell death upon glutamine deprivation. Cancer cell 2012;22(5):631-44. https://doi.org/10.1016/j.ccr.2012.09.021.

[48] Ren P, Yue M, Xiao D, Xiu R, Gan L, Liu H et al. ATF4 and N-Myc coordinate glutamine metabolism in MYCN-amplified neuroblastoma cells through ASCT2 activation. The Journal of pathology 2015;235(1):90-100. https://doi.org/10.1002/path.4429.

[49] Yang S, Zheng J, Ma Y, Zhu H, Xu T, Dong K et al. Oct4 and Sox2 are overexpressed in human neuroblastoma and inhibited by chemotherapy. Oncology reports 2012;28(1):186-92. https://doi.org/10.3892/or.2012.1765.

[50] Gifford CA, Ziller MJ, Gu H, Trapnell C, Donaghey J, Tsankov A et al. Transcriptional and epigenetic dynamics during specification of human embryonic stem cells. Cell 2013;153(5):1149-63. https://doi.org/10.1016/j.cell.2013.04.037.

[51] Čančer M, Hutter S, Holmberg KO, Rosén G, Sundström A, Tailor J et al. Humanized Stem Cell Models of Pediatric Medulloblastoma Reveal an Oct4/mTOR Axis that 
Promotes Malignancy. Cell Stem Cell 2019;25(6):855-870.e11.

https://doi.org/10.1016/j.stem.2019.10.005.

[52] Påhlman S, Mohlin S. Hypoxia and hypoxia-inducible factors in neuroblastoma. Cell Tissue Res 2018;372(2):269-75. https://doi.org/10.1007/s00441-017-2701-1.

[53] Schaaf MB, Garg AD, Agostinis P. Defining the role of the tumor vasculature in antitumor immunity and immunotherapy. Cell death \& disease 2018;9(2):115. https://doi.org/10.1038/s41419-017-0061-0.

[54] Lugano R, Ramachandran M, Dimberg A. Tumor angiogenesis: causes, consequences, challenges and opportunities. Cell. Mol. Life Sci. 2020;77(9):1745-70. https://doi.org/10.1007/s00018-019-03351-7.

[55] Leprivier G, Rotblat B, Khan D, Jan E, Sorensen PH. Stress-mediated translational control in cancer cells. Biochimica et biophysica acta 2015;1849(7):845-60. https://doi.org/10.1016/j.bbagrm.2014.11.002.

\section{FIGURE LEGENDS}

Figure 1: EIF4EBP1 mRNA expression is associated with MYCN mRNA expression and is increased in more advanced and aggressive NB subsets.

(a) Expression levels of EIF4EBP1 mRNA in a pool of four different NB cohorts (total $n=203$ ), compared to healthy control tissues (adrenal gland, $n=13$ ). (b, c) Expression levels of EIF4EBP1 mRNA n MYCN-amplified ( $\mathrm{n}=92$, SEQC [b] and $\mathrm{n}=93$, Kocak [c]) compared to MYCN-non-amplified ( $\mathrm{n}=401$, SEQC [b] and $\mathrm{n}=550$ Kocak [c]) NB patients of the SEQC (b) and Kocak (c) cohorts. (d, e) Expression levels of EIF4EBP1 mRNA plotted against expression levels of MYCN mRNA in SEQC $(r=0.5637, d)$ and Kocak $(r=0.5321, e)$ cohorts. $(\mathrm{f}, \mathrm{g})$ Expression levels of EIF4EBP1 mRNA per NB stage in SEQC (f) and Kocak (g) cohorts. (h) Expression levels of EIF4EBP1 mRNA in high-risk $(\mathrm{n}=176)$ compared to nonhigh-risk ( $n=322)$ NB in the SEQC cohort. Data were retrieved from the R2: Genomics Analysis and Visualization Platform. Statistics were determined using Mann-Whitney U-test. Exact $p$-values are presented. ${ }^{*} P<0.05,{ }^{* *} P<0.01,{ }^{* *} P<0.001,{ }^{* * *} P<0.0001$. 
Figure 2: EIF4EBP1 mRNA expression correlates with overall survival in NB patients. (a-c) Kaplan-Meier survival estimates of overall survival of NB patients stratified by their EIF4EBP1 mRNA expression levels (median cut off) in the SEQC (a), Kocak (b) and NRC (c) cohorts. (d-h) Kaplan-Meier survival estimates of overall survival of patients with $M Y C N$-nonamplified NB (d, e), high-risk NB (f) or stage 4 NB $(g, h)$ stratified by their EIF4EBP1 mRNA expression levels in the indicated NB cohorts. The number of patients at risk (or censored) are reported under the Kaplan-Meier plot by four-year intervals; such information were not accessible for the Kocak cohort. Significance was determined by log rank test. Data were obtained from the R2: Genomics Analysis and Visualization Platform.

Figure 3: 4EBP1 protein expression is associated with histological subtype of NB.

(a) Representative images of low (left panel) and high (right panel) 4EBP1 immunohistochemical staining levels of selected NB samples represented on the NB TMAs. (b) Distribution of NB cases showing low (IRS 0-6) versus high (IRS 7-12) 4EBP1 protein expression in prognostically favorable versus unfavorable histological subtypes according to International Neuroblastoma Pathology Classification (INPC). Fisher's exact test was used to calculate significance. ${ }^{*} P<0.05$.

Figure 4: EIF4EBP1 promoter activity and expression is regulated by MYCN.

(a) ChIP peaks of MYCN in the EIF4EBP1 promoter region in Kelly NB cell line. (b) Scheme of the EIF4EBP1 promoter reporter highlighting the three E-boxes corresponding to MYCN binding sites. (c) HEK-293-T were transfected with wildtype or different E-box mutants EIF4EBP1 promoter Firefly Luciferase constructs with or without a MYCN expressing plasmid (pMYCN). A Renilla Luciferase vector was used as an internal control. (d, e) Relative MYCN and EIF4EBP1 mRNA levels upon siRNA-mediated knockdown of MYCN in the MYCN-amplified IMR-32 (d) and Kelly (e) cell lines, as measured by qRT-PCR. (f, g) SHEPTR-MYCN cells were treated with doxycycline $(1 \mu \mathrm{g} / \mathrm{ml})$ for the indicated times; EIF4EBP1 
mRNA levels were determined by qRT-PCR (f) and levels of MYCN and 4EBP1 proteins were monitored by immunoblot using the indicated antibodies (g). (h) Relative EIF4EBP1 mRNA expression in healthy control tissues (ganglia, $n=9)$ and NB tumors $(n=26)$ of a THMYCN transgenic mouse model of NB (Balamuth's dataset; [44]). Data were retrieved from the R2: Genomics Analysis and Visualization Platform. Statistics were determined using Student's t-test or Mann-Whitney U-test. Exact p-values are presented. ${ }^{*} P<0.05,{ }^{\star *} P<0.01$, ${ }^{\star \star *} P<0.001,{ }^{* \star \star} P<0.0001$.

\section{SUPPLEMENTARY FIGURE LEGENDS}

Supplementary Figure 1: EIF4EBP1 mRNA expression correlates with event-free survival in NB patients.

(a-b) Kaplan-Meier survival estimates of event-free survival of NB patients stratified by their EIF4EBP1 mRNA expression levels (median cut off) in the SEQC (a), Kocak (b) and NRC (c) cohorts. (d-h) Kaplan-Meier estimates of event-free survival of patients with MYCN-nonamplified NB (d, e), high-risk NB (f) or stage 4 NB $(g, h)$ stratified by their EIF4EBP1 mRNA expression levels in the indicated NB cohorts. The number of patients at risk (or censored) are reported under the Kaplan-Meier plot by four-year intervals; such information were not accessible for the Kocak cohort. Significance was determined by log rank test. Data were obtained from the R2: Genomics Analysis and Visualization Platform.

Supplementary Figure 2: MYCN stimulates EIF4EBP1 promoter activity and 4EBP1 protein expression in a dose-dependent manner.

(a) HEK-293-T cells were transfected with the wildtype EIF4EBP1 promoter Firefly Luciferase construct and with the indicated amounts of MYCN expressing plasmid (pMYCN). A Renilla Luciferase vector was used as an internal control. (b) MYCN and 4EBP1 protein expression was monitored in cell lysates from (a) by immunoblot analyses using the indicated antibodies. 
bioRxiv preprint doi: https://doi.org/10.1101/2021.12.08.471784; this version posted December 9, 2021. The copyright holder for this preprint (which was not certified by peer review) is the author/funder, who has granted bioRxiv a license to display the preprint in perpetuity. It is made available under aCC-BY-NC-ND 4.0 International license.

\section{TABLES}

Table 1. Multivariate analysis for overall survival of NB patients in the SEQC cohort.

Table 2. Multivariate analysis for overall survival of NB patients in the NRC cohort. 
bioRxiv preprint doi: https://doi.org/10.1101/2021.12.08.471784; this version posted December 9, 2021. The copyright holder for this preprint (which was not certified by peer review) is the author/funder, who has granted bioRxiv a license to display the preprint in perpetuity. It is made available under aCC-BY-NC-ND 4.0 International license.

$\mathbf{a}$

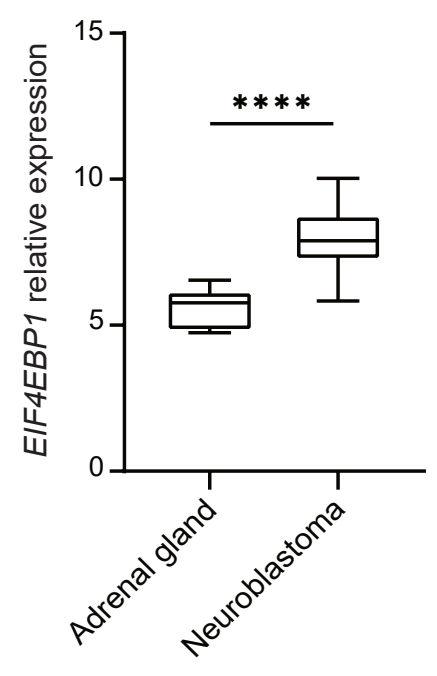

d

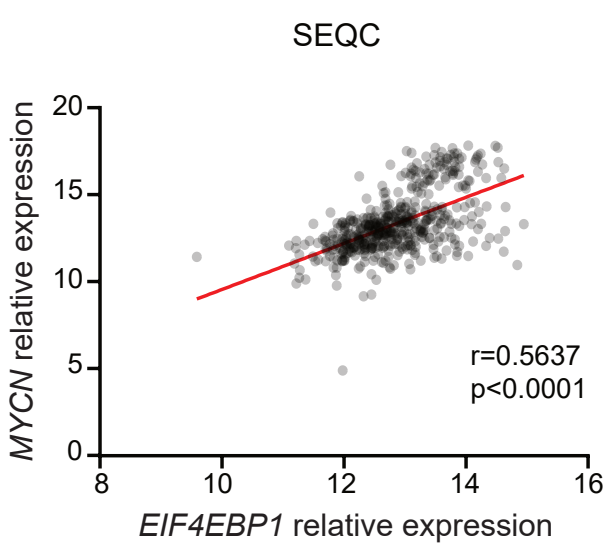

g

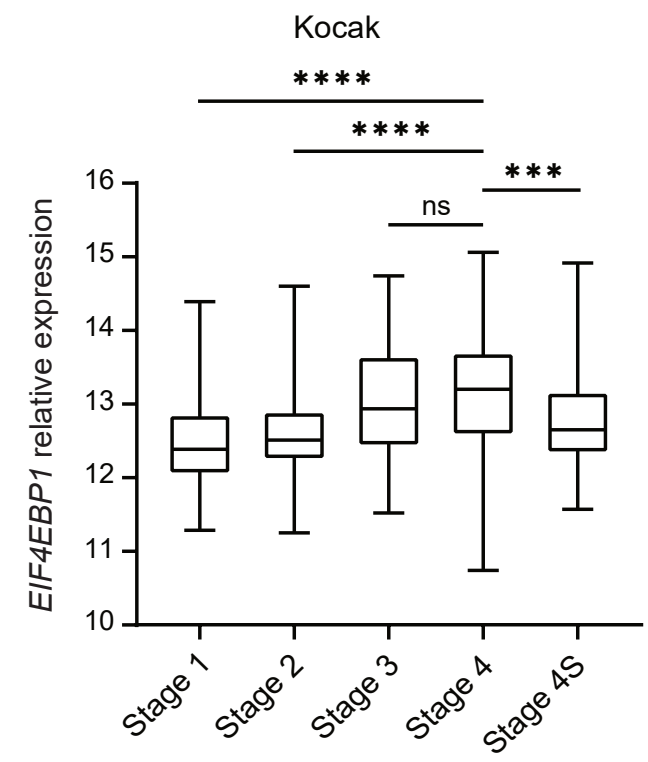

b

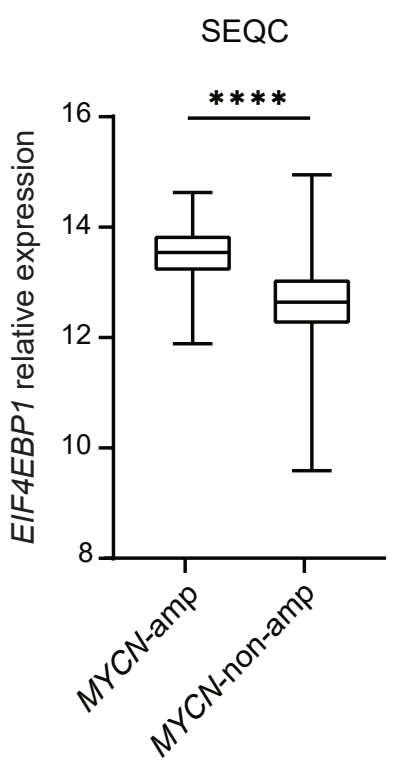

e

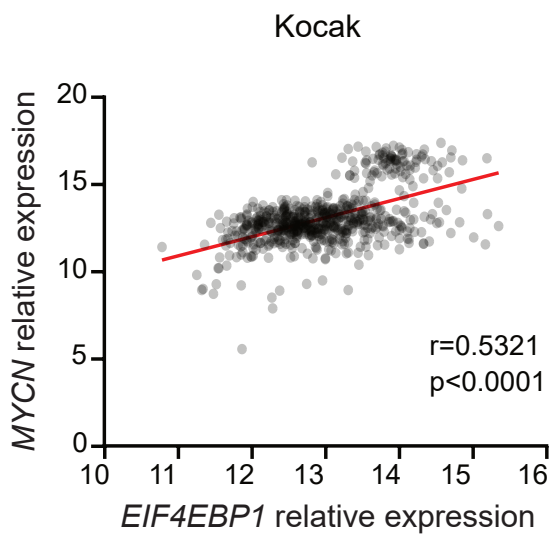

c

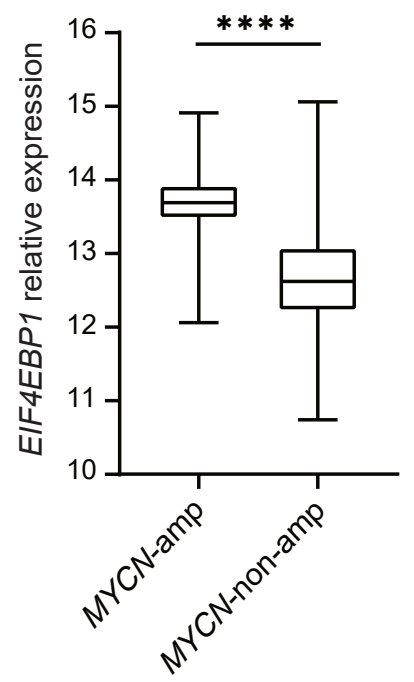

SEQC
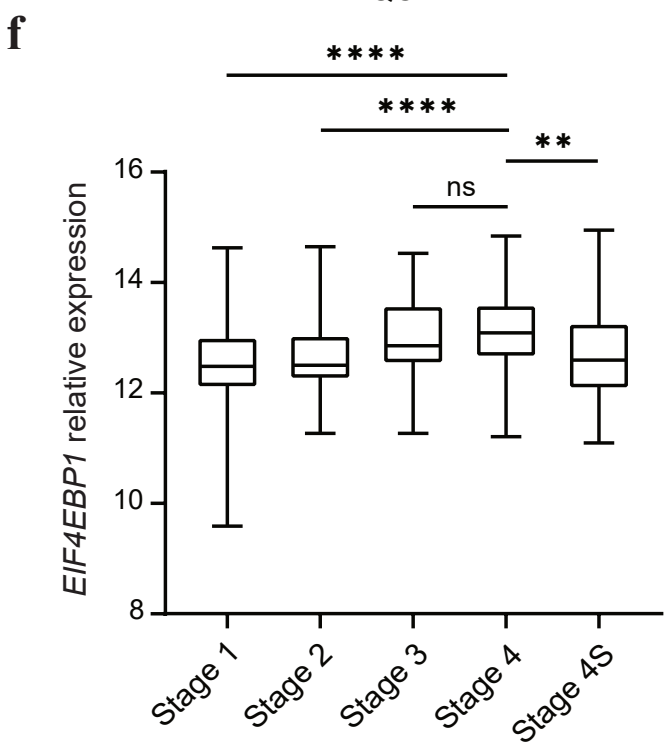

h

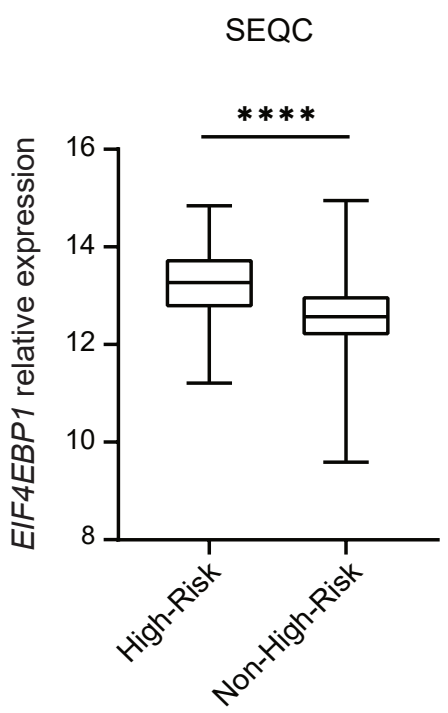


bioRxiv preprint doi: https://g_exg10.1101/2021.12.08.471784; this Ygrsion posted December 9, 2021. The egpyright holder for this

Figure 2

作

Number at risk (censored) Time (months)

c

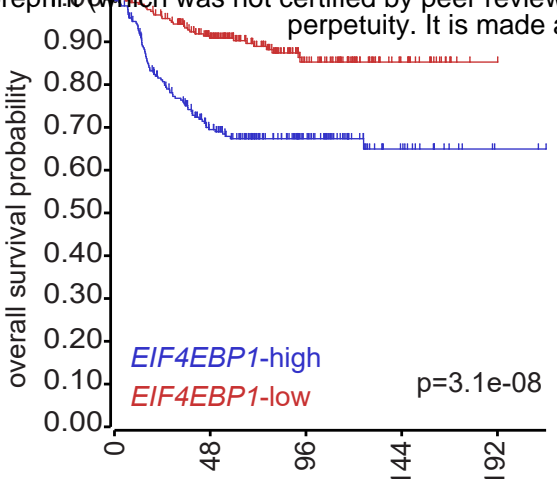

$\begin{array}{llllll}\text { EIF4EBP1-high } & 249 & 140 & 63 & 17 & 2 \\ & & (37) & (110) & (155) & (170) \\ \text { EIF4EBP1-low } & 249 & 181 & 76 & 23 & 1 \\ & & (47) & (145) & (198) & (220)\end{array}$

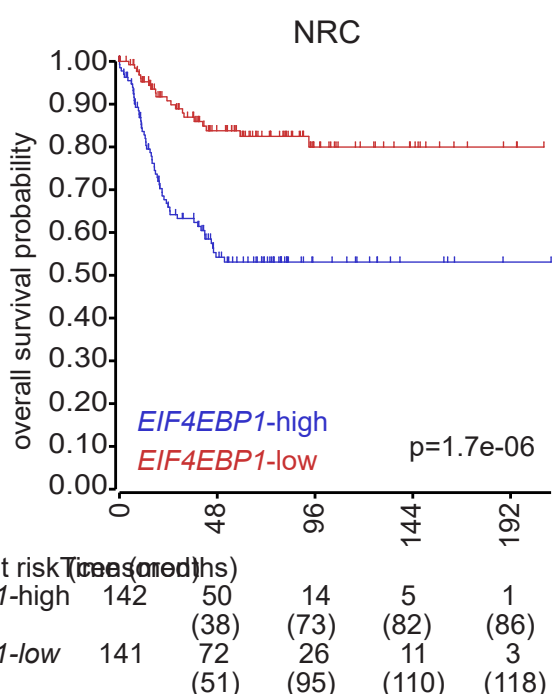

d

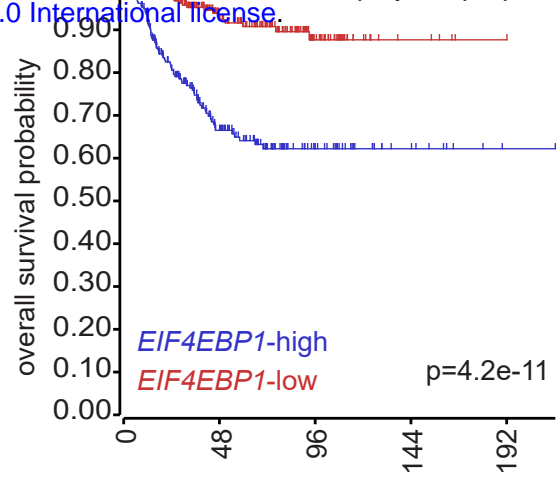

$\mathbf{f}$

h
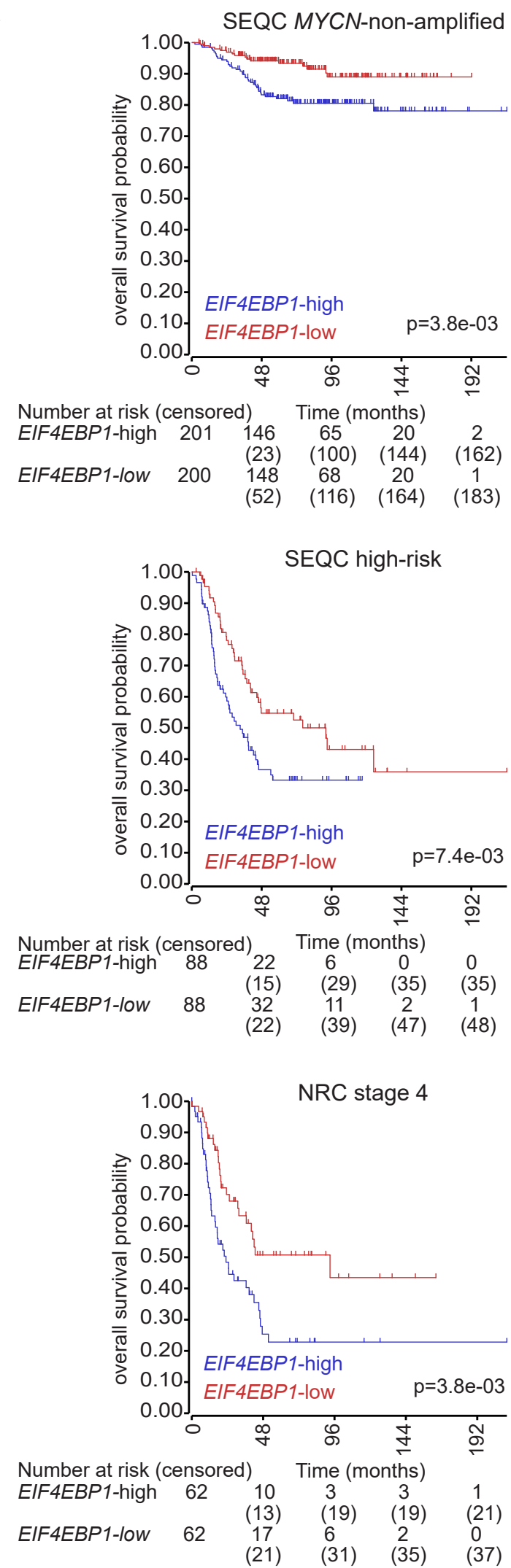
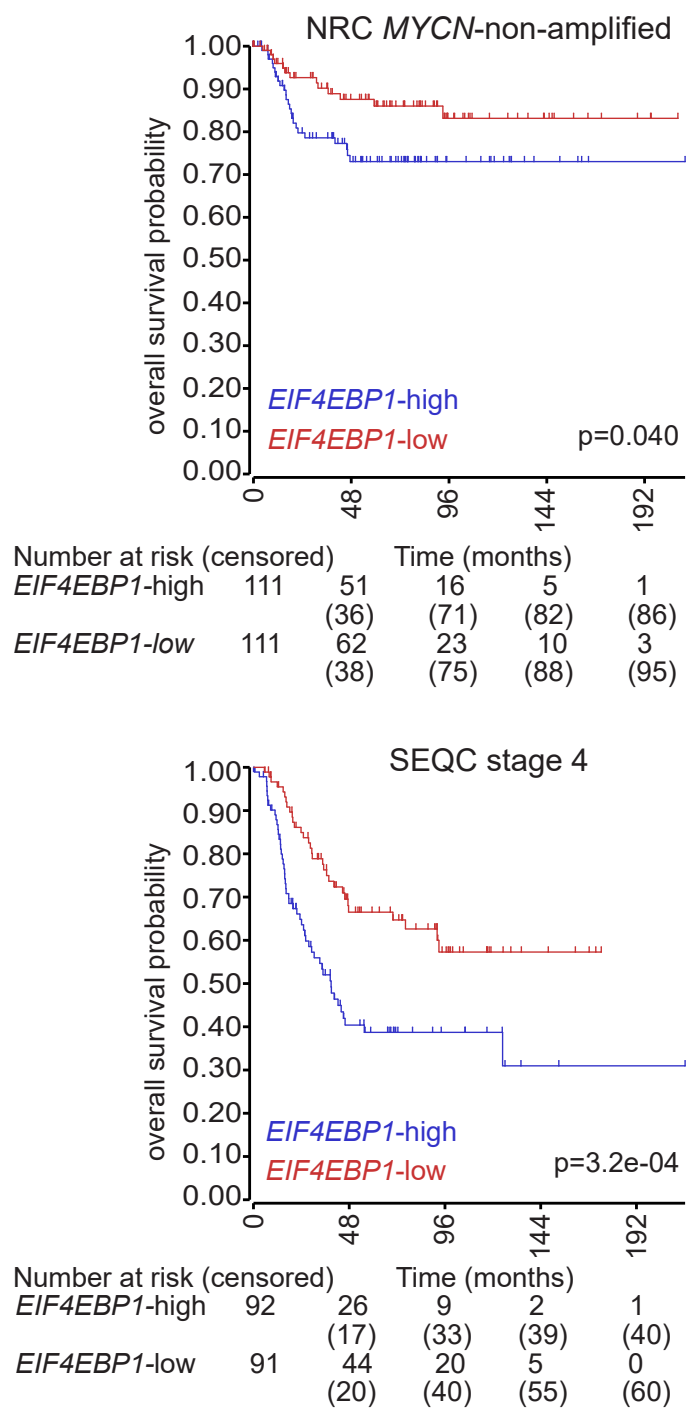

Number at risk (censored) Time (months)

EIF4EBP1-high $111 \quad 51 \quad 16 \quad 501$

$\begin{array}{lccccc} & & (36) & (71) & (82) & (86) \\ \text { EIF4EBP1-low } & 111 & 62 & 23 & 10 & 3\end{array}$

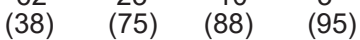

g 
a

\section{low 4EBP1}

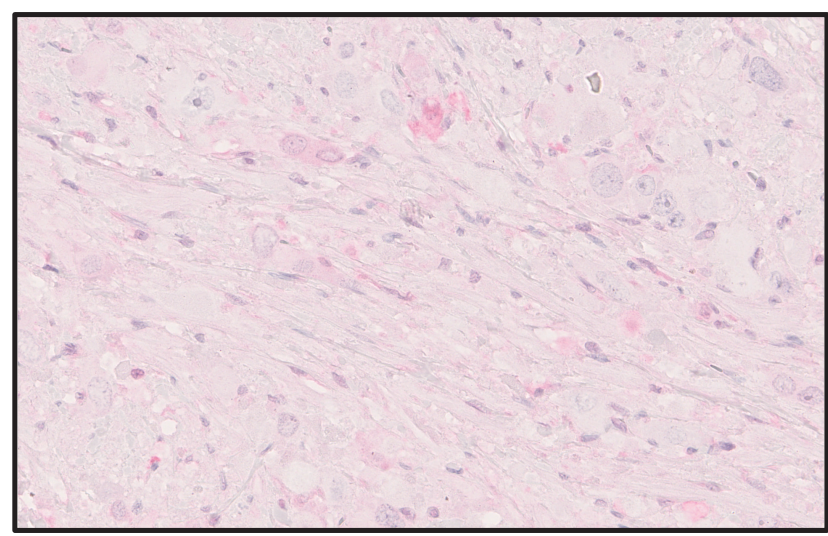

high 4EBP1

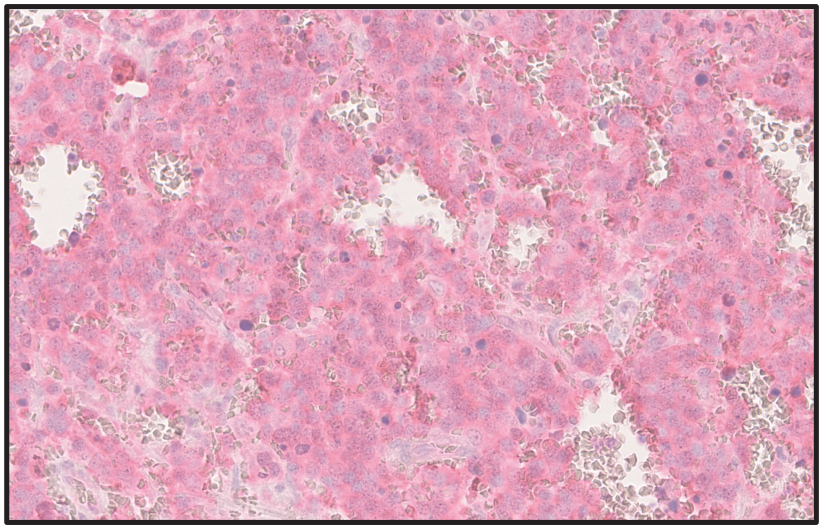

b

4EBP1 intensity vs. INPC classification

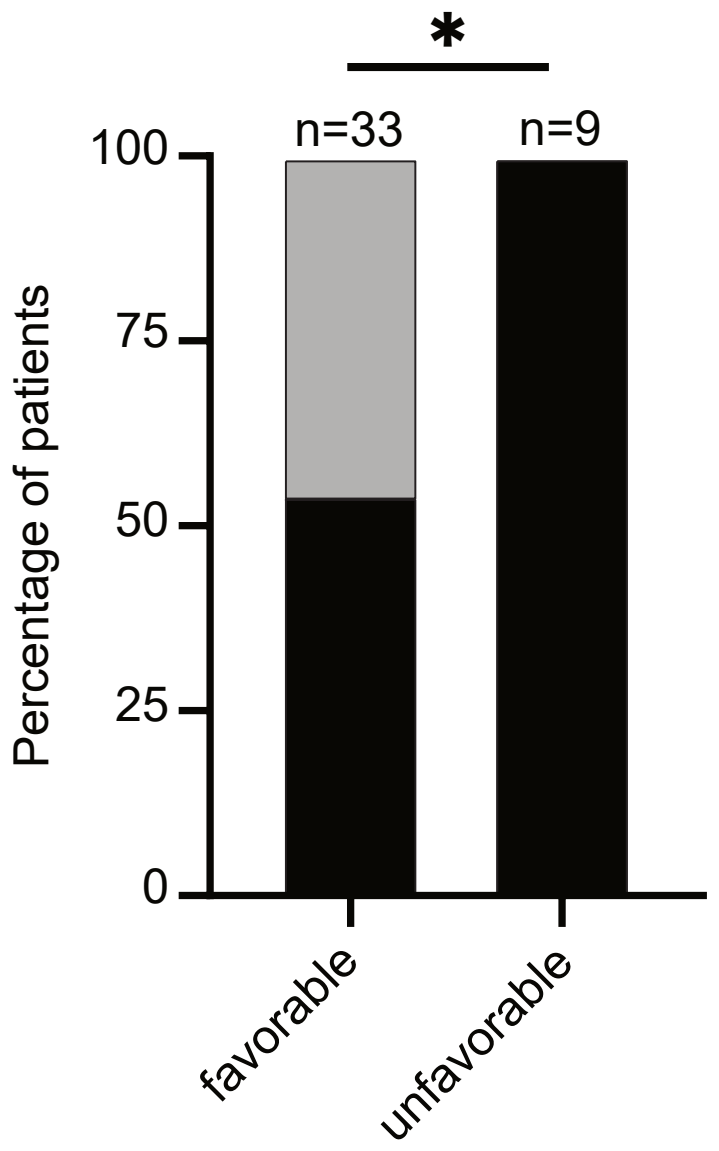

Iow 4EBP1

high 4EBP1 
b

$\underset{-192}{\hdashline}$

c

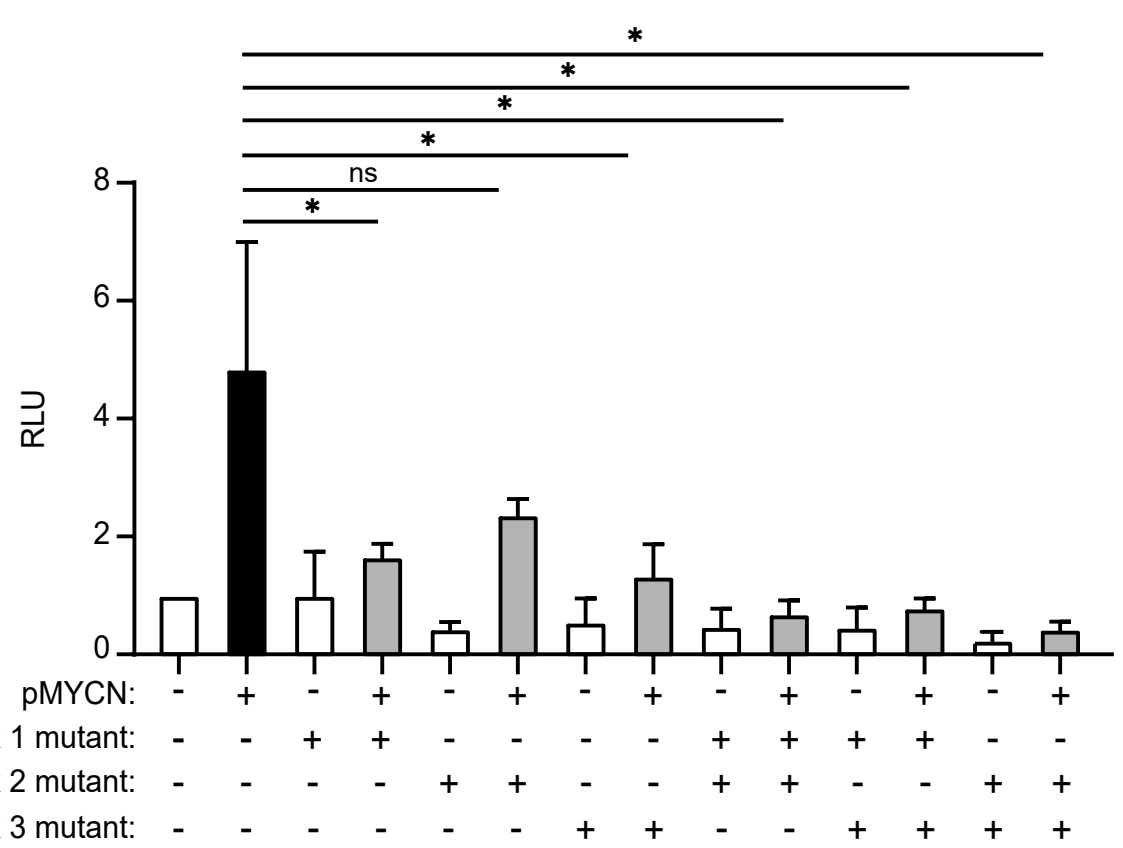

e
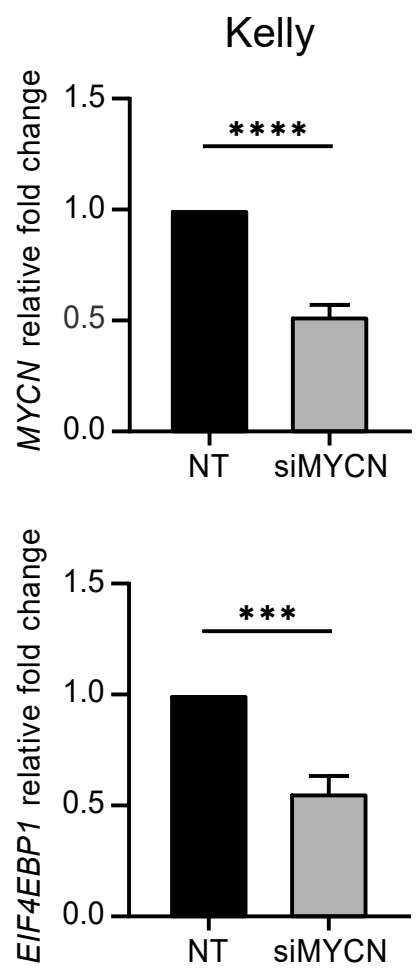

\section{f}

\section{SHEP-TR-MYCN}

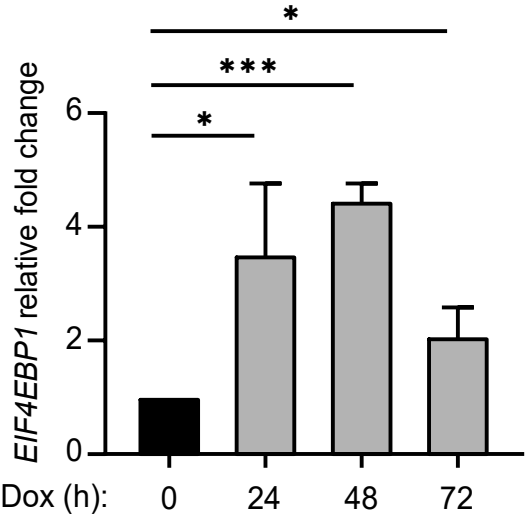

g

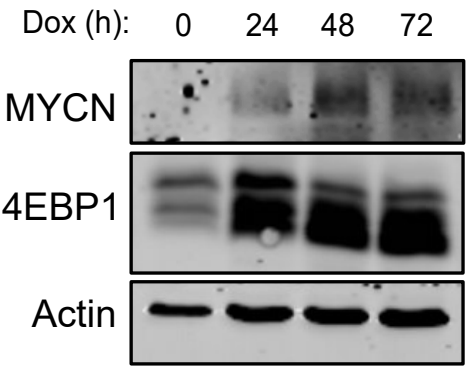

d IMR-32
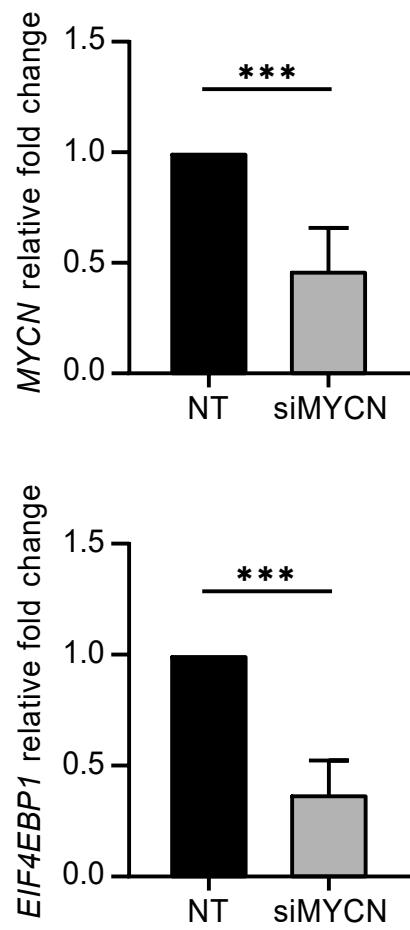

h

Balamuth

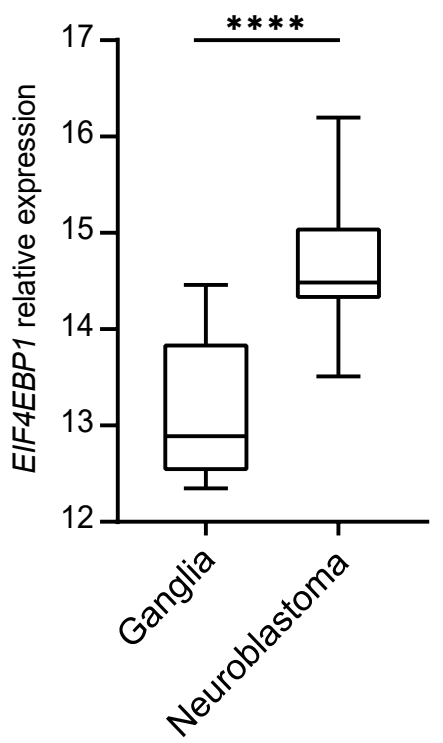


bioRxiv preprint doi: https://doi.org/10.1101/2021.12.08.471784; this yersion posted December 9, 2021. The copyright hołdepPlementary Figure 1

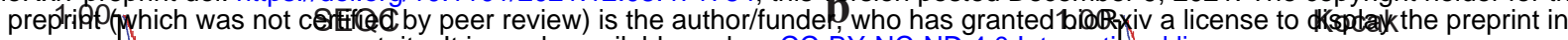

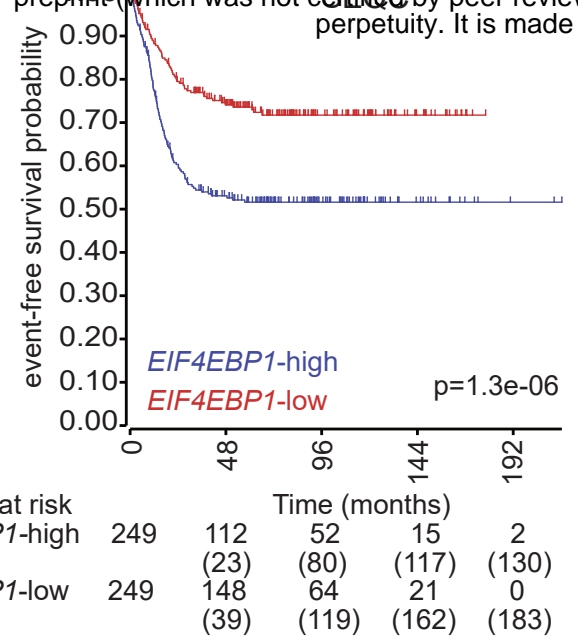

$$
\begin{array}{llcccc}
\begin{array}{l}
\text { Number at risk } \\
\text { elF4EBP1-high }
\end{array} & \multirow{5}{c}{\text { Time (months) }} \\
& & 112 & 52 & 15 & 2 \\
\text { elF4EBP1-low } & 249 & (23) & (80) & (117) & (130) \\
& & (39) & (119) & (162) & (183)
\end{array}
$$

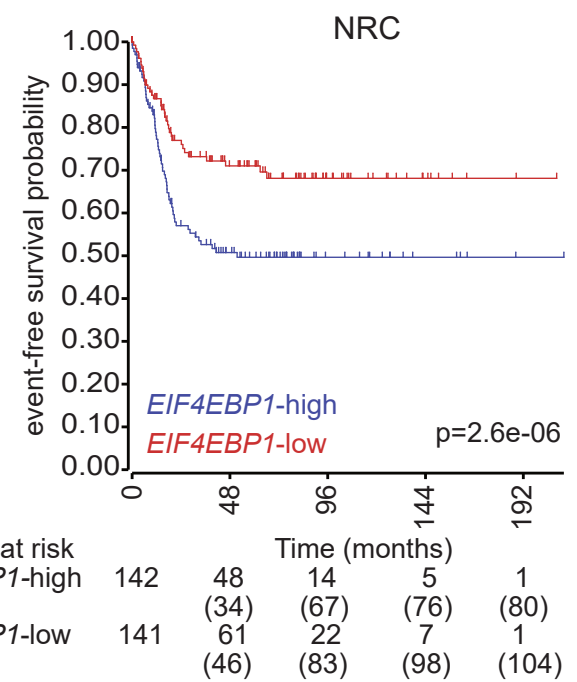

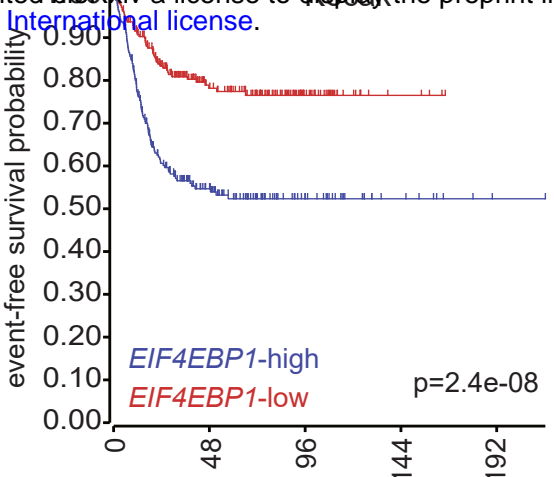

d

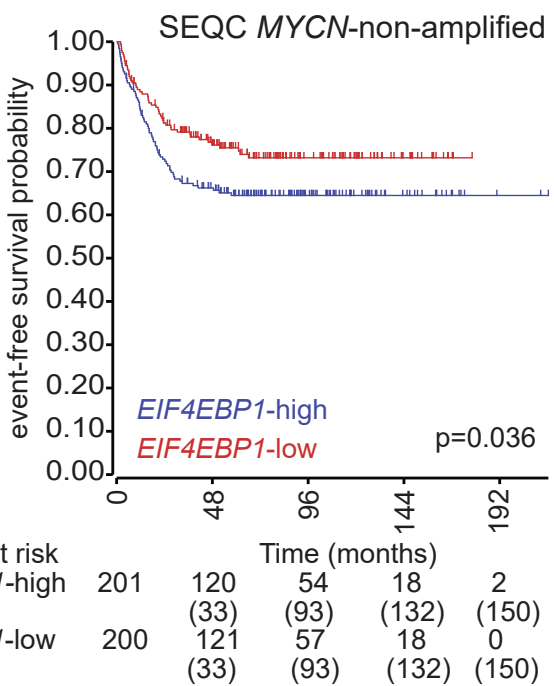

e

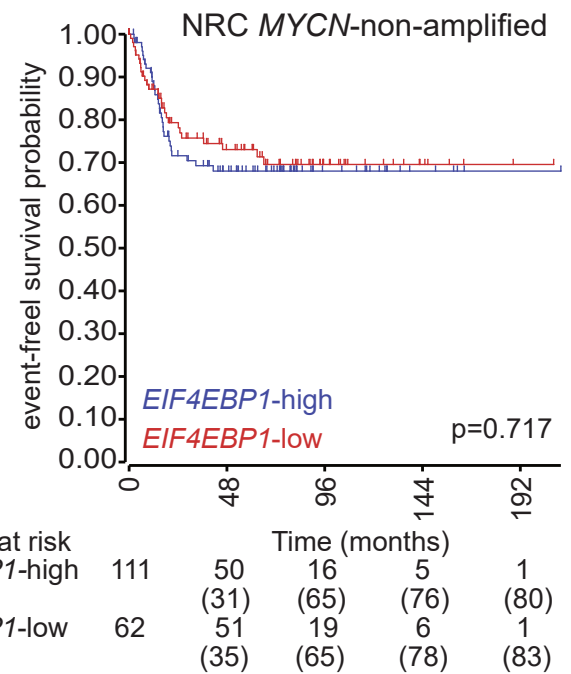

g

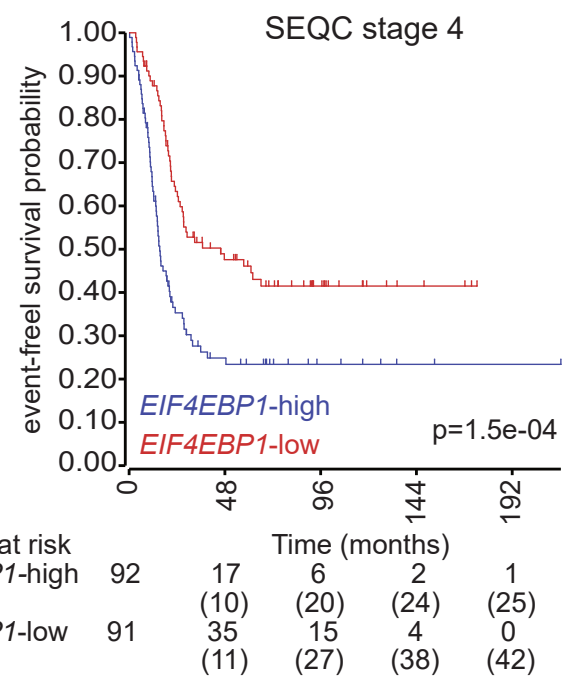

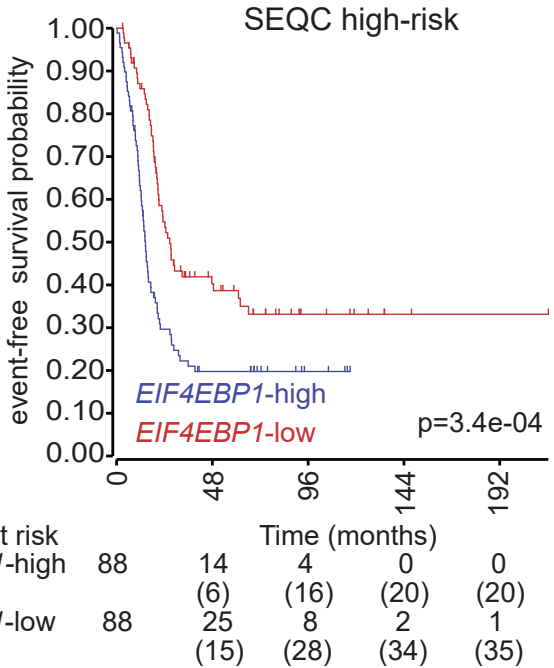

h

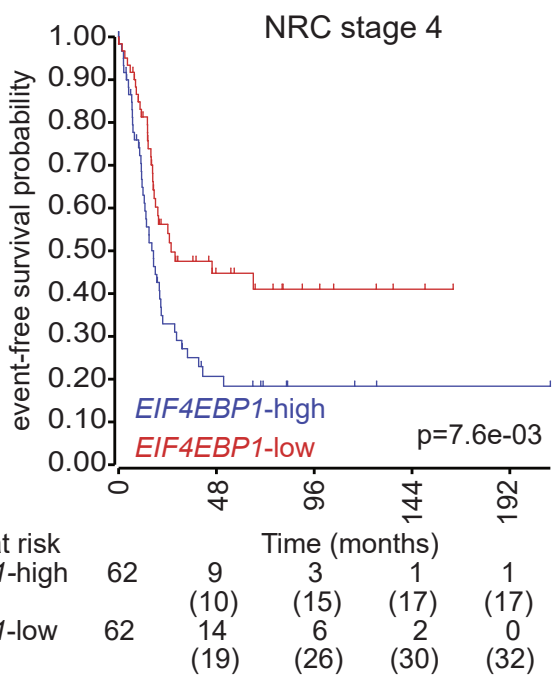


bioRxiv preprint doi: https://doi.org/10.1101/2021.12.08.471784; this version posted December 9, 2021. The copyright holp9plenthisitary Figure 2 preprint (which was not certified by peer review) is the author/funder, who has granted bioRxiv a license to display the preprint in perpetuity. It is made available under aCC-BY-NC-ND 4.0 International license.

HEK-293-T

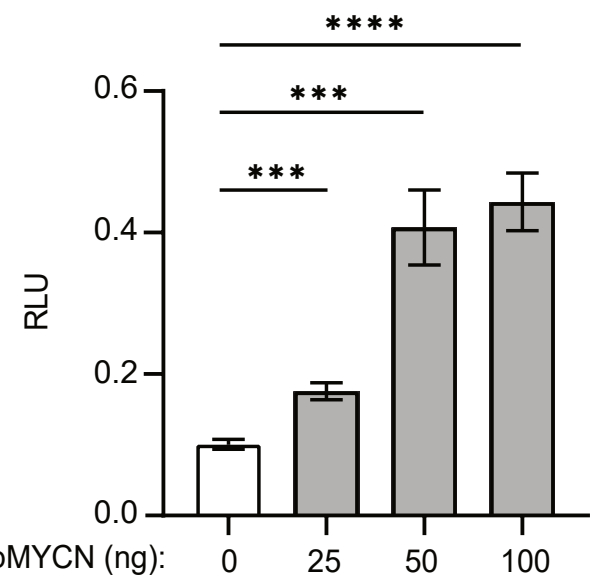

HEK-293-T

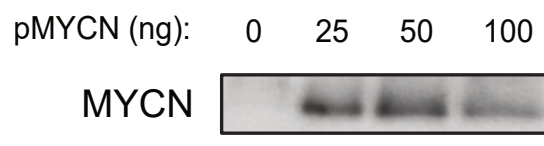

4EBP1

Actin 
Table 1. Multivariate analysis for overall survival of NB patients in the SEQC cohort.

\begin{tabular}{|l|l|l|l|}
\hline Variables & HR & $\mathbf{9 5 . 0 \% ~ C l}$ & p value \\
\hline MYCN amplification & 22.373 & $8.89-56.306$ & 0 \\
\hline High EIF4EBP1 mRNA expression & 2.16 & $1.255-3.717$ & 0.005 \\
\hline MYCN amplification*high EIF4EBP1 mRNA expression & 0.222 & $0.08-0.614$ & 0.004 \\
\hline & & & \\
\hline Variables & HR & $\mathbf{9 5 . 0 \% ~ C l}$ & p value \\
\hline Stage 4 & 17.618 & $6.694-46.366$ & 0 \\
\hline High EIF4EBP1 mRNA expression & 5.457 & $2.026-14.697$ & 0.001 \\
\hline Stage 4*high EIF4EBP1 mRNA expression & 0.292 & $0.097-0.879$ & 0.029 \\
\hline & & & \\
\hline Variables & HR & $\mathbf{9 5 . 0 \% ~ C l}$ & $\mathbf{p}$ value \\
\hline Age at diagnosis & 33.018 & $7.835-139.139$ & 0 \\
\hline High EIF4EBP1 mRNA expression & 12.204 & $2.832-52.598$ & 0.001 \\
\hline Age at diagnosis*high EIF4EBP1 mRNA expression & 0.16 & $0.035-0.74$ & 0.019 \\
\hline
\end{tabular}


Table 2. Multivariate analysis for overall survival of NB patients in the NRC cohort.

\begin{tabular}{|l|l|l|l|}
\hline Variables & $\mathbf{H R}$ & $\mathbf{9 5 . 0 \%} \mathbf{C l}$ & $\mathbf{p}$ value \\
\hline MYCN amplification & 4.967 & $1.118-22.066$ & 0.035 \\
\hline High EIF4EBP1 mRNA expression & 3.031 & $1.543-5.954$ & 0.001 \\
\hline MYCN amplification*high EIF4EBP1 mRNA expression & 0.656 & $0.135-3.181$ & 0.601 \\
\hline & & & \\
\hline Variables & $\mathbf{H R}$ & $\mathbf{9 5 . 0 \%} \mathbf{C l}$ & $\mathbf{p}$ value \\
\hline Stage 4 & 15.050 & $4.239-53.432$ & 0.018 \\
\hline High EIF4EBP1 mRNA expression & 5.144 & $1.330-19.895$ & 0 \\
\hline Stage 4*high EIF4EBP1 mRNA expression & 0.36 & $0.081-1.598$ & 0.179 \\
\hline & & & \\
\hline Variables & $\mathbf{H R}$ & $\mathbf{9 5 . 0 \%} \mathbf{C l}$ & $\mathbf{p}$ value \\
\hline Age at diagnosis & 0.27 & $0.036-2.056$ & 0 \\
\hline High EIF4EBP1 mRNA expression & 0.364 & $0.048-2.772$ & 0.002 \\
\hline Age at diagnosis*high EIF4EBP1 mRNA expression & 55.427 & $3.258-942.88$ & 0.005 \\
\hline
\end{tabular}




\section{Supplementary table 1: Primer list}

\begin{tabular}{|lcc|}
\hline Target gene & \multicolumn{1}{c|}{ Forward } & Reverse \\
\hline elF4EBP1 & AGCCCTTCCAGTGATGAGC & TGTCCATCTCAAACTGTGACTCTT \\
\hline $\boldsymbol{M Y C N}$ & TGAGCGATTCAGATGATGAAGA & GCATCGTTTGAGGATCAGC \\
\hline GUSB & GTTTTTGATCCAGACCCAGATG & GCCCATTATTCAGAGCGAGTA \\
\hline $\boldsymbol{P P I A}$ & TTATTTGGGTTGCTCCCTTC & AAGTGTGCCAAATCTGCAAG \\
\hline
\end{tabular}

